\title{
Chiroptical Asymmetric Reaction Screening via Multicomponent Self-Assembly
}

\author{
Zeus A. De los Santos and Christian Wolf* \\ Department of Chemistry, Georgetown University, Washington, DC 20057, USA
}

\section{Contents:}

$\begin{array}{ll}\text { 1. Synthetic procedures } & \text { S2 }\end{array}$

2. Chiroptical sensing $\quad$ S5

3. Mechanistic study of the assembly process $\quad$ S17

4. Quantitative ee and concentration analysis of $5 \quad$ S22

5. Quantitative ee and concentration analysis of $23 \quad$ S26

6. Ee and concentration analysis of amine 23 obtained S30

by enantioselective hydrogenation of 1-phenylethan-1-iminium chloride 26

7. Crystallographic data $\quad$ S35

8. References $\quad$ S35 


\section{Synthetic procedures}

All commercially available reagents and solvents were used without further purification. Reactions were carried out under inert and anhydrous conditions. Flash chromatography was performed on silica gel, particle size 40-63 $\mu \mathrm{m}$. NMR spectra were obtained at $400 \mathrm{MHz}\left({ }^{1} \mathrm{H}\right.$ $\mathrm{NMR})$ and $100 \mathrm{MHz}\left({ }^{13} \mathrm{C} \mathrm{NMR}\right)$ using $\mathrm{CDCl}_{3}$ as solvent. Compounds $\mathbf{2}$ and $\mathbf{3}$ were prepared according to literature procedures. ${ }^{1}$
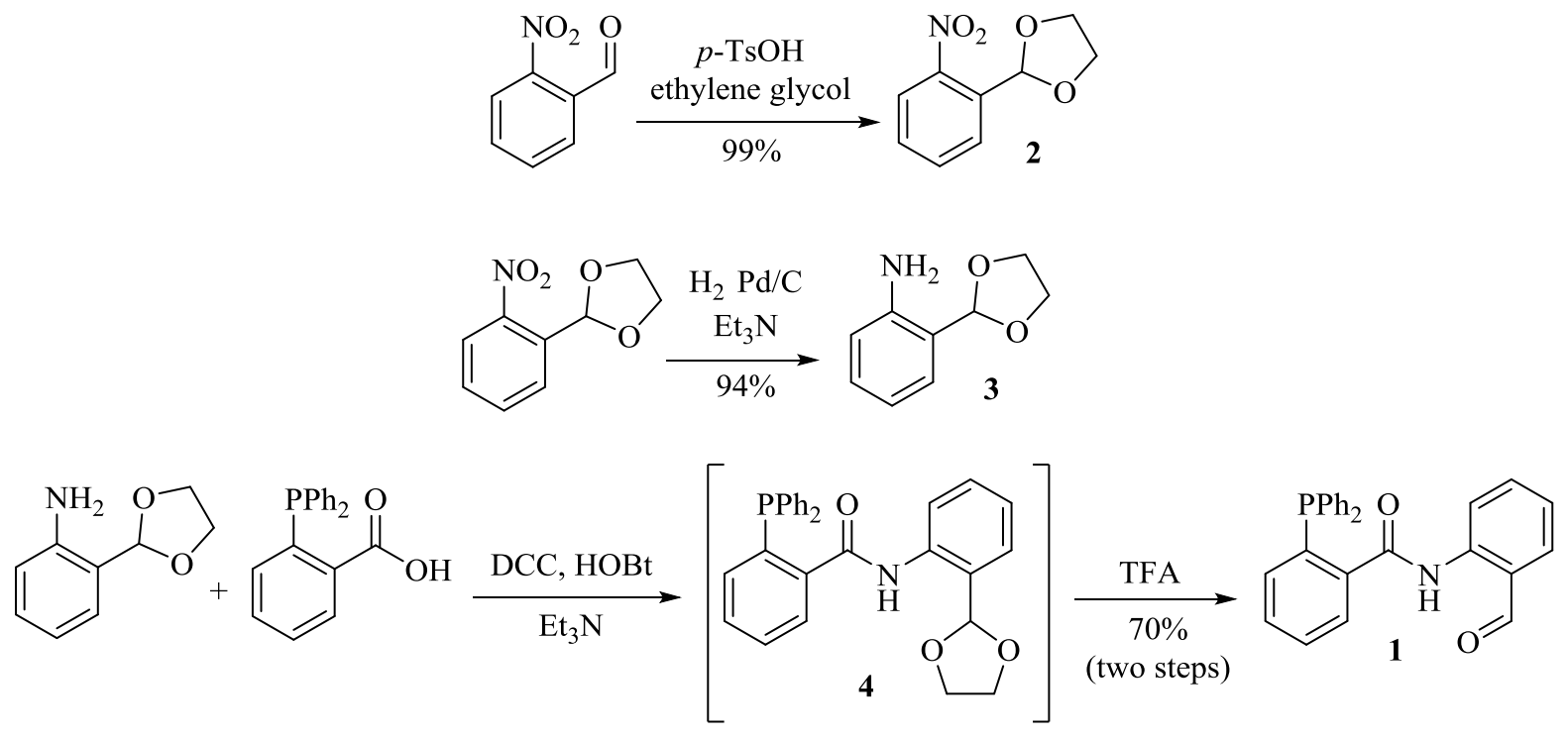

\section{$N$-(2-(1,3-Dioxolan-2-yl)phenyl)-2-(diphenylphosphanyl)benzamide (4)}

2-(Diphenylphosphanyl)benzoic acid $(316 \mathrm{mg}, 1.03 \mathrm{mmol})$ was dissolved in $10 \mathrm{~mL}$ of anhydrous $\mathrm{CHCl}_{3}$. Triethylamine $(229 \mathrm{mg}, 2.26 \mathrm{mmol}$ ) was subsequently added and the solution was stirred for 5 minutes. $N, N^{\prime}$-Dicylohexylcarbodiimide (254 mg, $1.23 \mathrm{mmol}$ ) and hydroxybenzotriazole $(189 \mathrm{mg}, 1.23 \mathrm{mmol})$ previously dissolved in $5 \mathrm{~mL}$ of $\mathrm{CHCl}_{3}$ were added and the solution was cooled to $0{ }^{\circ} \mathrm{C}$. After one hour, the solution was allowed to warm to room temperature and 2-(1,3-dioxolan-2-yl)aniline $(170 \mathrm{mg}, 1.03 \mathrm{mmol})$ dissolved in $5 \mathrm{~mL}$ of $\mathrm{CHCl}_{3}$ was added. The solution was stirred at room temperature until completion. The mixture was then diluted with $20 \mathrm{~mL}$ of $\mathrm{CH}_{2} \mathrm{Cl}_{2}$ and washed with $20 \mathrm{~mL}$ of saturated sodium bicarbonate solution. The combined organic layers were washed with $20 \mathrm{~mL}$ of deionized water, dried over $\mathrm{Na}_{2} \mathrm{SO}_{4}$ and concentrated in vacuo. The crude product was used without further purification. 


\section{2-(Diphenylphosphanyl)- $N$-(2-formylphenyl)benzamide (1)}

Trifluoroacetic acid $(2.35 \mathrm{~g}, 20.60 \mathrm{mmol})$ was added to a solution of (4) in $20 \mathrm{~mL}$ of anhydrous THF and was stirred at room temperature for 18 hours. The reaction mixture was quenched with $10 \mathrm{~mL}$ of saturated sodium bicarbonate solution. The organic layer was washed with $20 \mathrm{~mL}$ of deionized water, dried over $\mathrm{Na}_{2} \mathrm{SO}_{4}$ and concentrated in vacuo. Purification by flash chromatography on silica gel (5\% EtOAc in hexanes) afforded $295 \mathrm{mg}$ $(0.72 \mathrm{mmol}, 70 \%)$ of a white powder. ${ }^{1} \mathrm{H}$ NMR: $\delta=7.08(\mathrm{dd}, J=8.1 \mathrm{~Hz}, 1 \mathrm{H}), 7.23(\mathrm{dd}, J=$ $7.6 \mathrm{~Hz}, 7.6 \mathrm{~Hz}, 2 \mathrm{H}), 7.31(\mathrm{~m}, 10 \mathrm{H}), 7.39$ (dd, $J=7.7 \mathrm{~Hz}, 7.5 \mathrm{~Hz}, 1 \mathrm{H}), 7.49$ (dd, $J=7.5 \mathrm{~Hz}$, $6.8 \mathrm{~Hz}, 1 \mathrm{H}), 7.58(\mathrm{dd}, J=8.1 \mathrm{~Hz}, 7.9 \mathrm{~Hz}, 1 \mathrm{H}), 7.68(\mathrm{~d}, J=7.9 \mathrm{~Hz}, 1 \mathrm{H}), 7.82(\mathrm{dd}, J=7.4 \mathrm{~Hz}$, $3.7 \mathrm{~Hz}, 1 \mathrm{H}), 8.75(\mathrm{~d}, J=7.7 \mathrm{~Hz}, 1 \mathrm{H}), 9.91$ (s, $1 \mathrm{H}), 11.62$ (bs, $1 \mathrm{H}) .{ }^{13} \mathrm{C}$ NMR: $\delta=120.4$, $122.0,123.2$, 127.2, 127.3, 128.5, 128.6, 128.7, 129.1, 130.1 130.9, 133.9, 134.1, 135.1, 136.0, 136.3, 137.7, 138.0, 141.0, 167.8, 195.6. Anal. Calcd. $\mathrm{C}_{26} \mathrm{H}_{20} \mathrm{NO}_{2} \mathrm{P}: \mathrm{C}, 76.27$; H, 4.92; N, 3.42. Found: C, 76.11; H, 5.28; N, 3.05.

${ }^{1} \mathrm{H}$ and ${ }^{13} \mathrm{C}$ NMR Spectra of $\mathbf{1}$ in $\mathrm{CDCl}_{3}$.

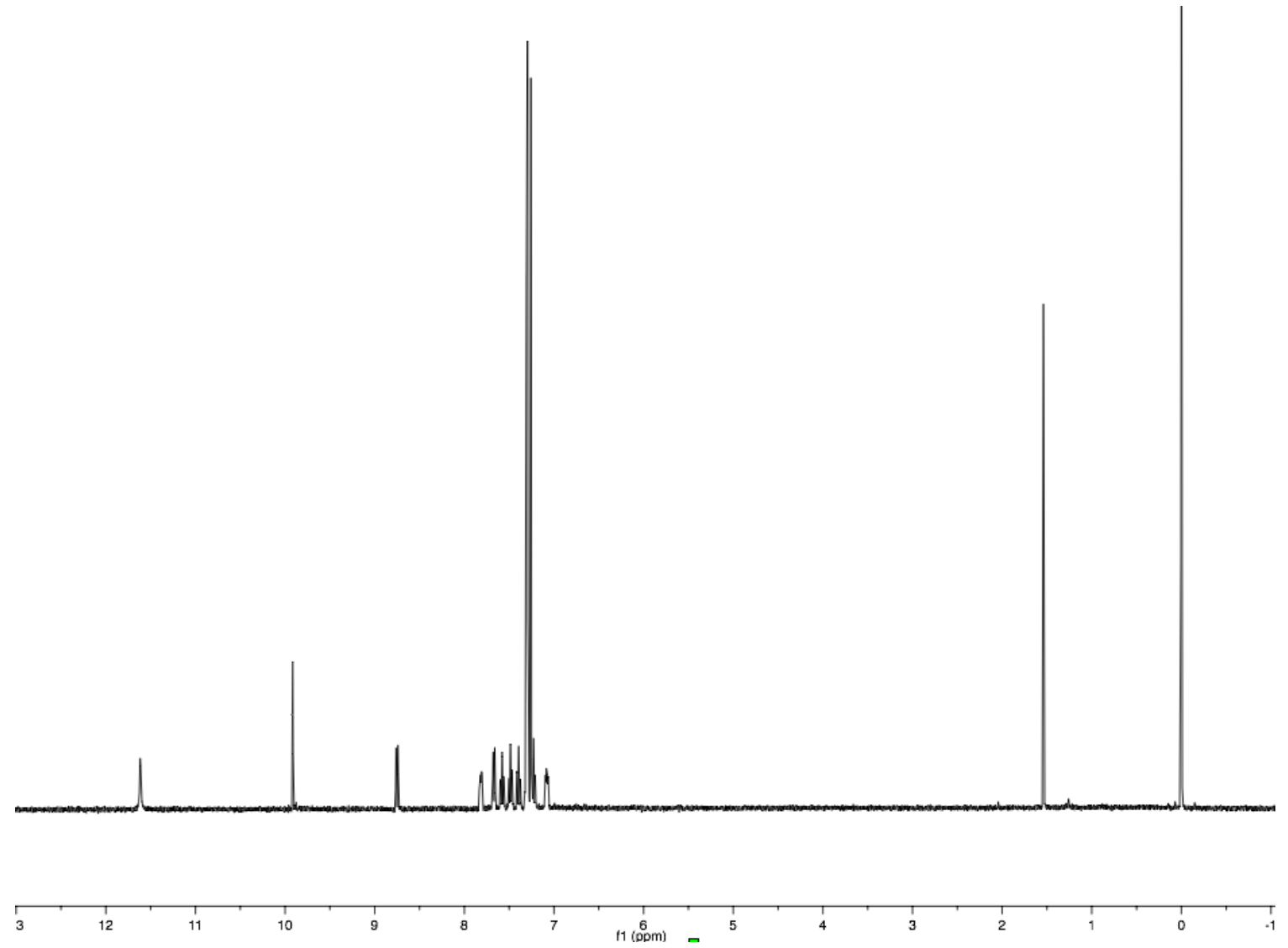




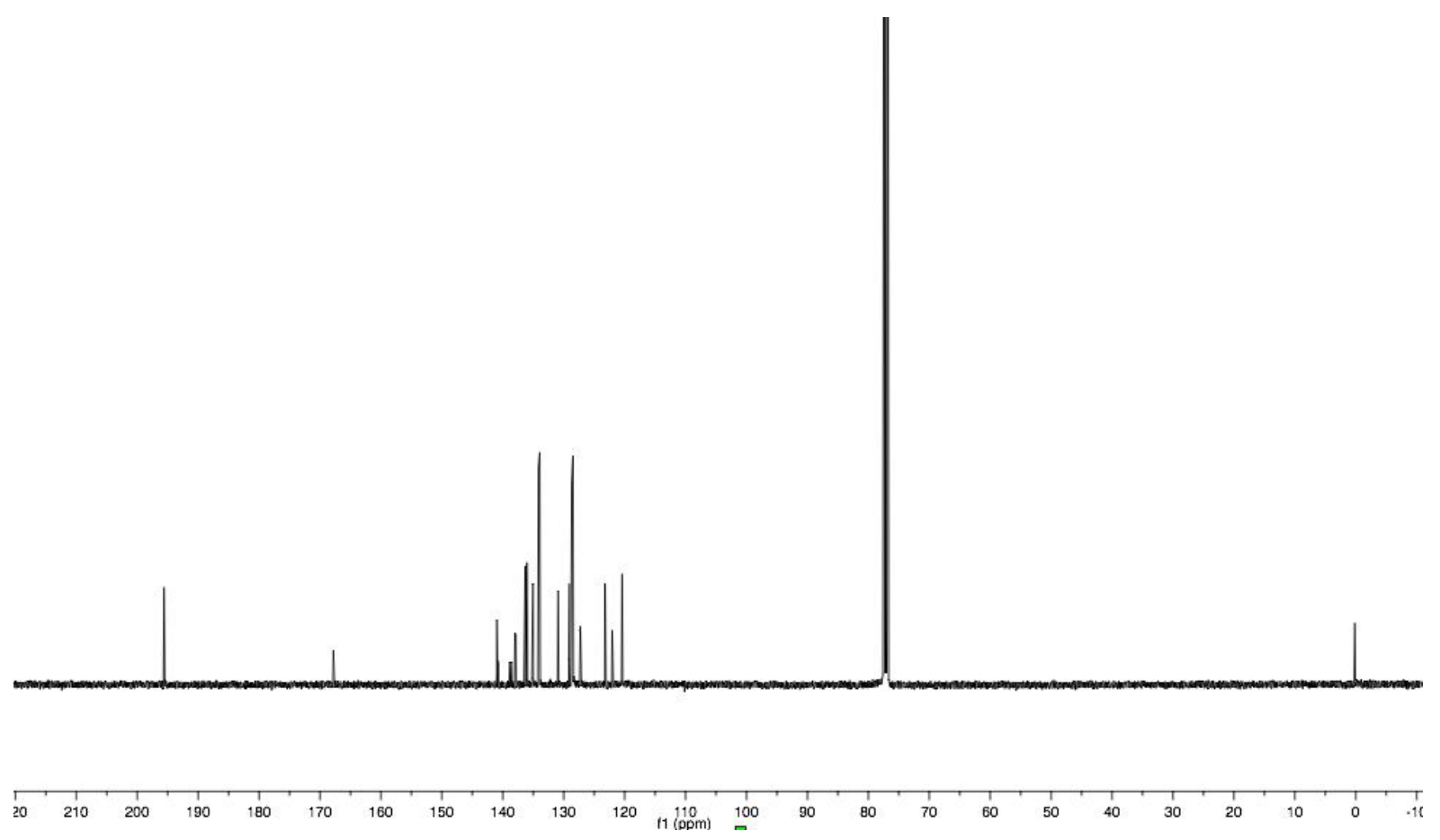




\section{Chiroptical sensing}

The general utility of $\mathbf{1}$ for enantioselective chemosensing was tested with amino acids 5-16, amino alcohols 17-20 and amines 21-25 (only one enantiomer shown).

1. Amino acids<smiles>N[C@@H](Cc1ccccc1)C(=O)O</smiles>

5<smiles>N[C@@H](Cc1cc2ccccc2[nH]1)C(=O)O</smiles>

6<smiles>C[C](N)C(=O)O</smiles>

7<smiles>CC(C)[C@H](N)C(=O)O</smiles>

8<smiles>CC(C)C[C@H](N)C(=O)O</smiles>

9<smiles>CSCCC(N)C(=O)O</smiles>

10<smiles>CC(O)[C@H](N)C(=O)O</smiles>

11<smiles>N[C@@H](CO)C(=O)O</smiles>

12<smiles>N[C@@H](Cc1ccc(O)cc1)C(=O)O</smiles>

13<smiles>N[C@@H](Cc1c[nH]cn1)C(=O)O</smiles>

14<smiles>NCCCC[C@H](N)C(=O)O</smiles>

15<smiles>NC(=O)CC[C@H](N)C(=O)O</smiles>

16

2. Amino alcohols<smiles>N[C@H](c1ccccc1)[C@H](O)c1ccccc1</smiles>

17<smiles>N[C@@H]1c2ccccc2C[C@H]1O</smiles>

18<smiles>N[C@@H](CO)c1ccccc1</smiles>

19<smiles>C[C](N)CO</smiles>

20

3. Amines<smiles>N[C@@H](c1ccccc1)[C@H](N)c1ccccc1</smiles>

21<smiles>N[C@@H]1CCCC[C@H]1N</smiles>

22<smiles>CC(N)c1ccccc1</smiles>

23<smiles>C[C@H](N)c1ccc2ccccc2c1</smiles>

24<smiles>C[C](N)C1CCCCC1</smiles>

25

A stock solution of $\mathbf{1}(0.01 \mathrm{M})$ in $\mathrm{CHCl}_{3}$ was prepared and portions of $0.5 \mathrm{~mL}$ were transferred to $4 \mathrm{~mL}$ vials. Solutions of the substrates were prepared by mixing an equimolar amount of amine and $\mathrm{TBAOH}(0.50 \mathrm{M}$ in $\mathrm{MeOH}$ ) (substrates 13, 15 and 16 required 2 equivalents of $\mathrm{TBAOH}$ to aid substrate solubility in $\mathrm{MeOH}$ ). To each vial containing $0.5 \mathrm{~mL}$ stock solution was added one equivalent $(0.01 \mathrm{~mL})$ of the substrate and one equivalent of $\mathrm{Pd}(\mathrm{OAc})_{2}$ dissolved in $\mathrm{CHCl}_{3}(0.02 \mathrm{~mL}, 0.25 \mathrm{M})$. The mixture was stirred for 30 minutes at $25^{\circ} \mathrm{C}$ and $\mathrm{CD}$ analysis was conducted with sample concentrations of $2.5 \times 10^{-4} \mathrm{M}$ in $\mathrm{CHCl}_{3}$. CD spectra were collected with a standard sensitivity of 100 mdeg, a data pitch of $2.0 \mathrm{~nm}$, a 
band width of $1 \mathrm{~nm}$, a scanning speed of $500 \mathrm{~nm} \mathrm{~s}^{-1}$ and a response of $0.5 \mathrm{~s}$ using a quartz cuvette ( $1 \mathrm{~cm}$ path length). The data were baseline corrected and smoothed using a binomial equation. Control experiments with 5-25 showed that the free substrates are CD silent in the region of interest.

CD Spectra of the assembly obtained from 1, Pd(OAc) 2 and L-5 (blue) or D-5 (red)

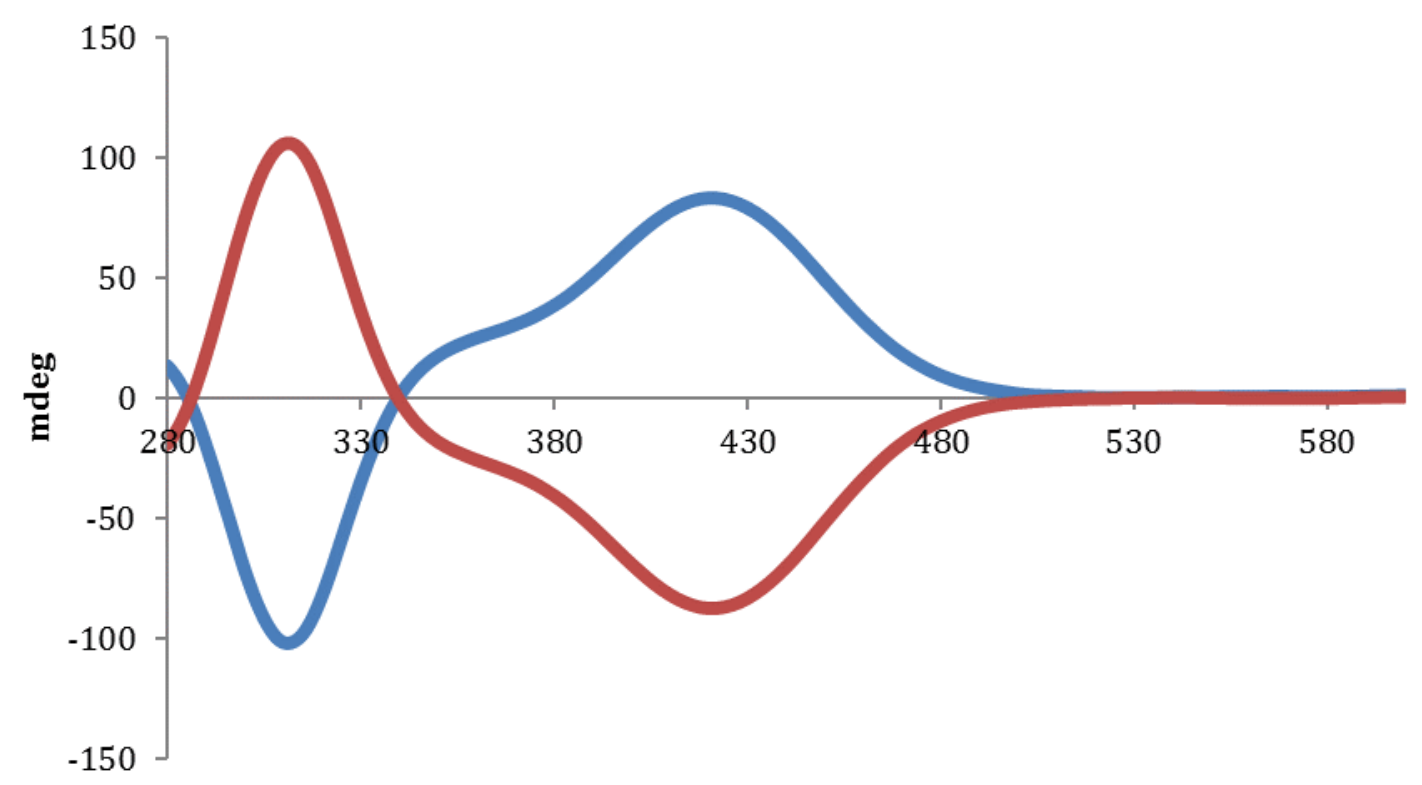

CD Spectra of the assembly obtained from 1, Pd(OAc) 2 and L-6 (blue) or D-6 (red)

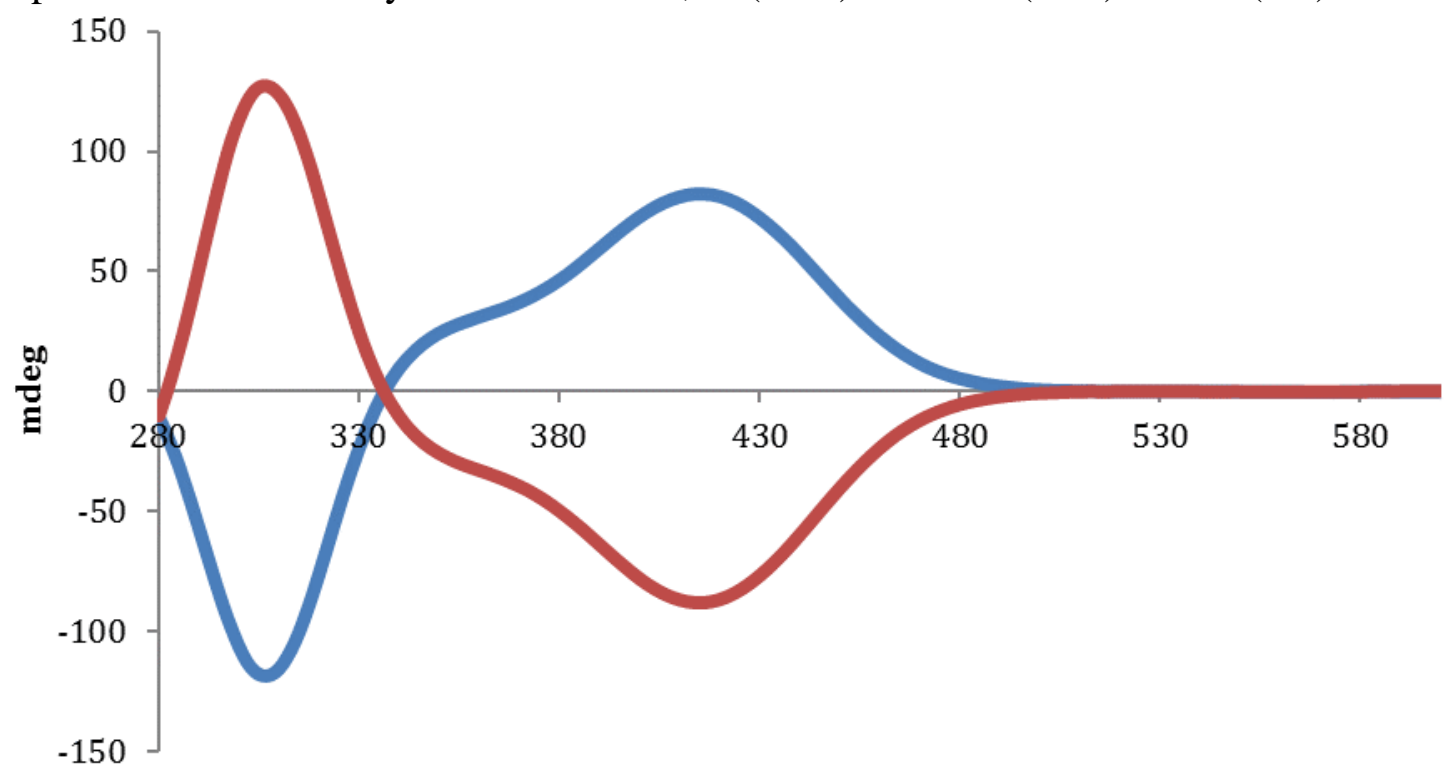


CD Spectra of the assembly obtained from 1, $\mathrm{Pd}(\mathrm{OAc})_{2}$ and L-7 (blue) or D-7 (red)

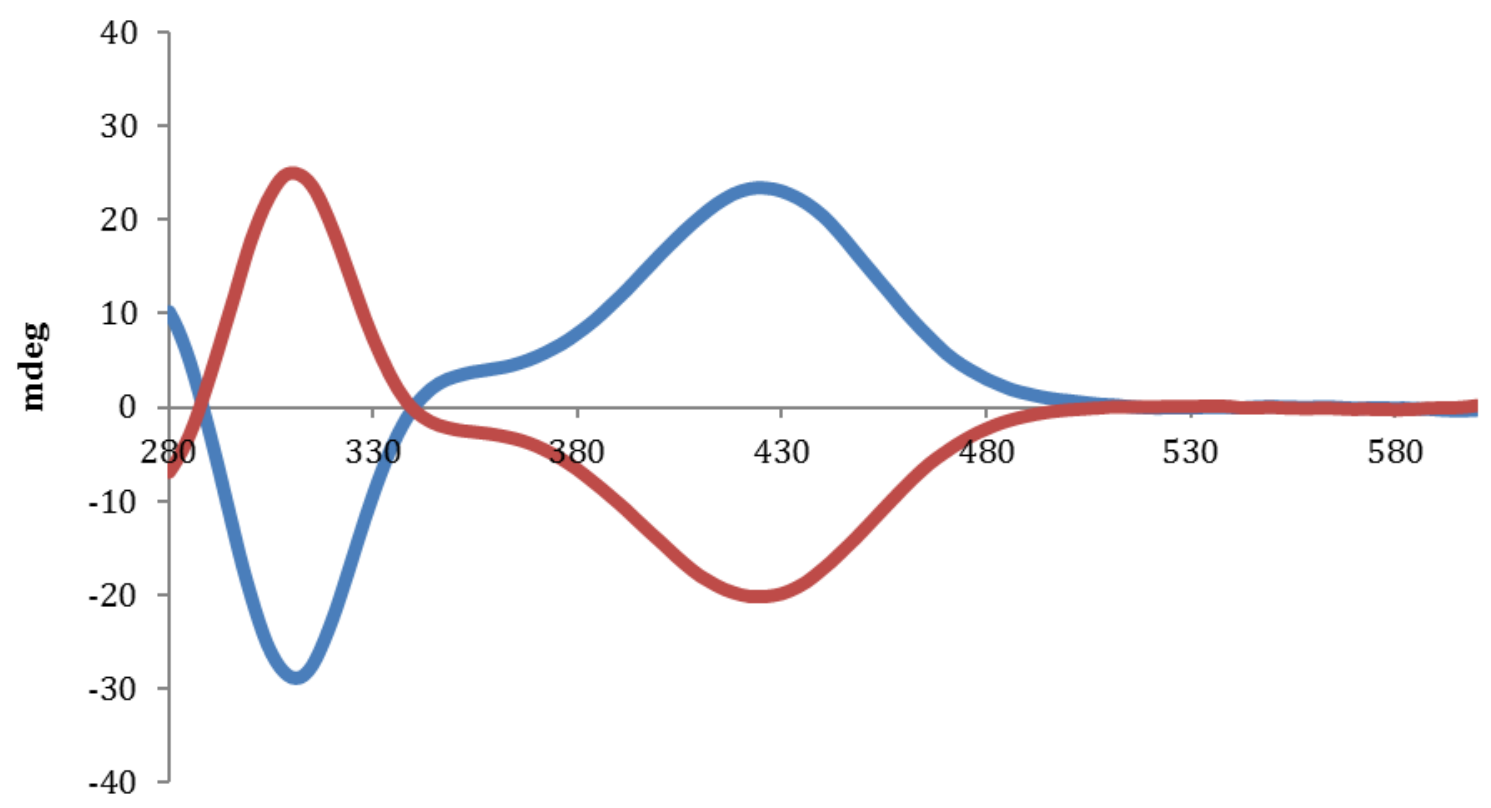

CD Spectra of the assembly obtained from 1, Pd(OAc) 2 and L-8 (blue) or D-8 (red)

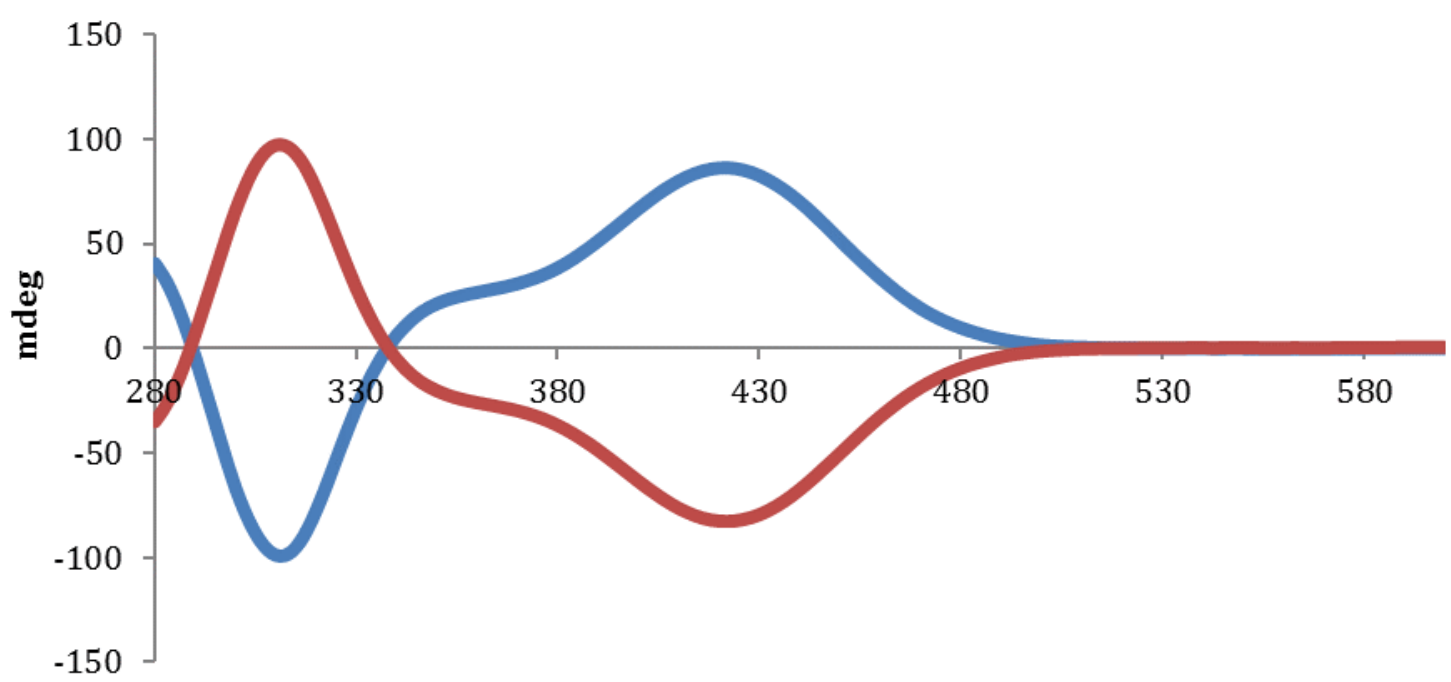


CD Spectra of the assembly obtained from 1, $\mathrm{Pd}(\mathrm{OAc})_{2}$ and L-9 (blue) or D-9 (red)

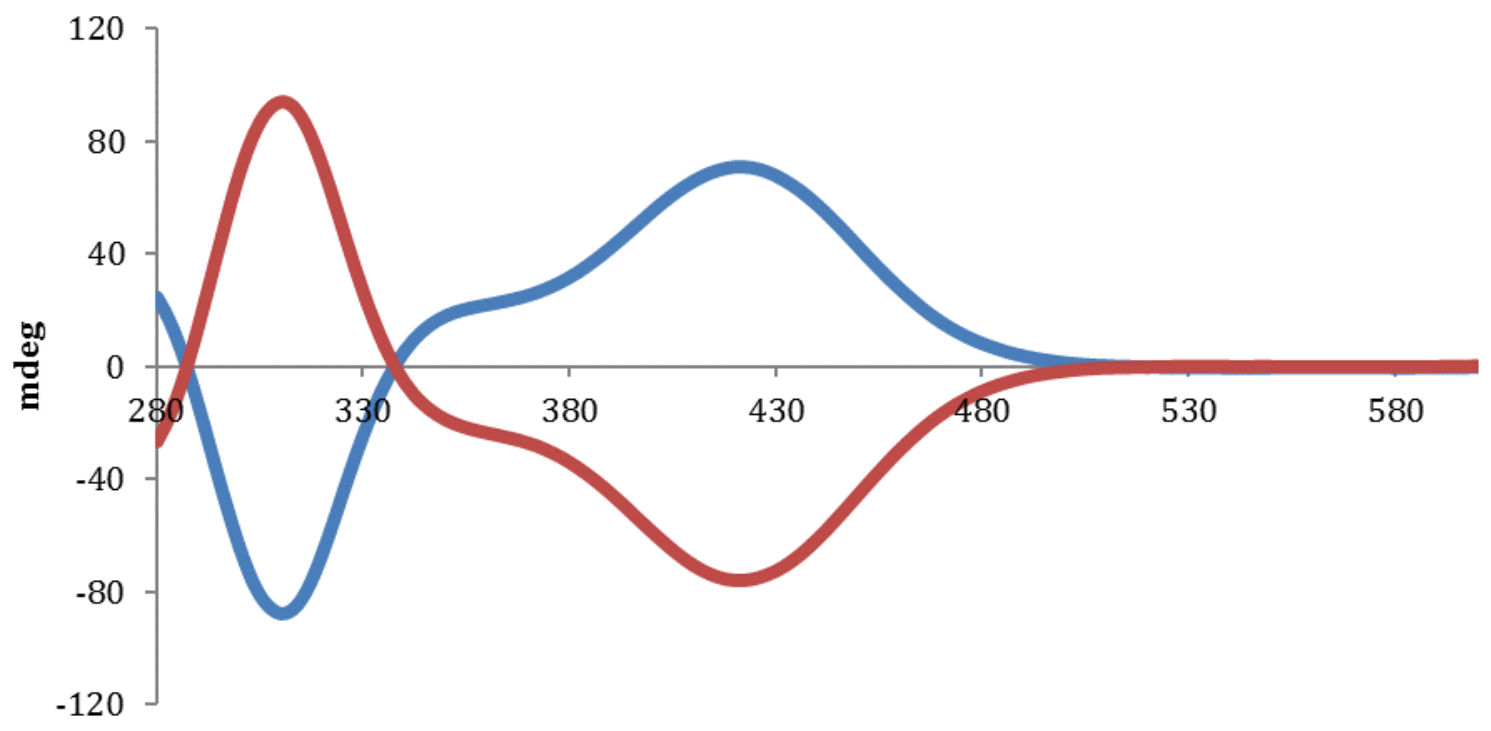

CD Spectra of the assembly obtained from 1, Pd(OAc) $)_{2}$ and L-10 (blue) or D-10 (red)

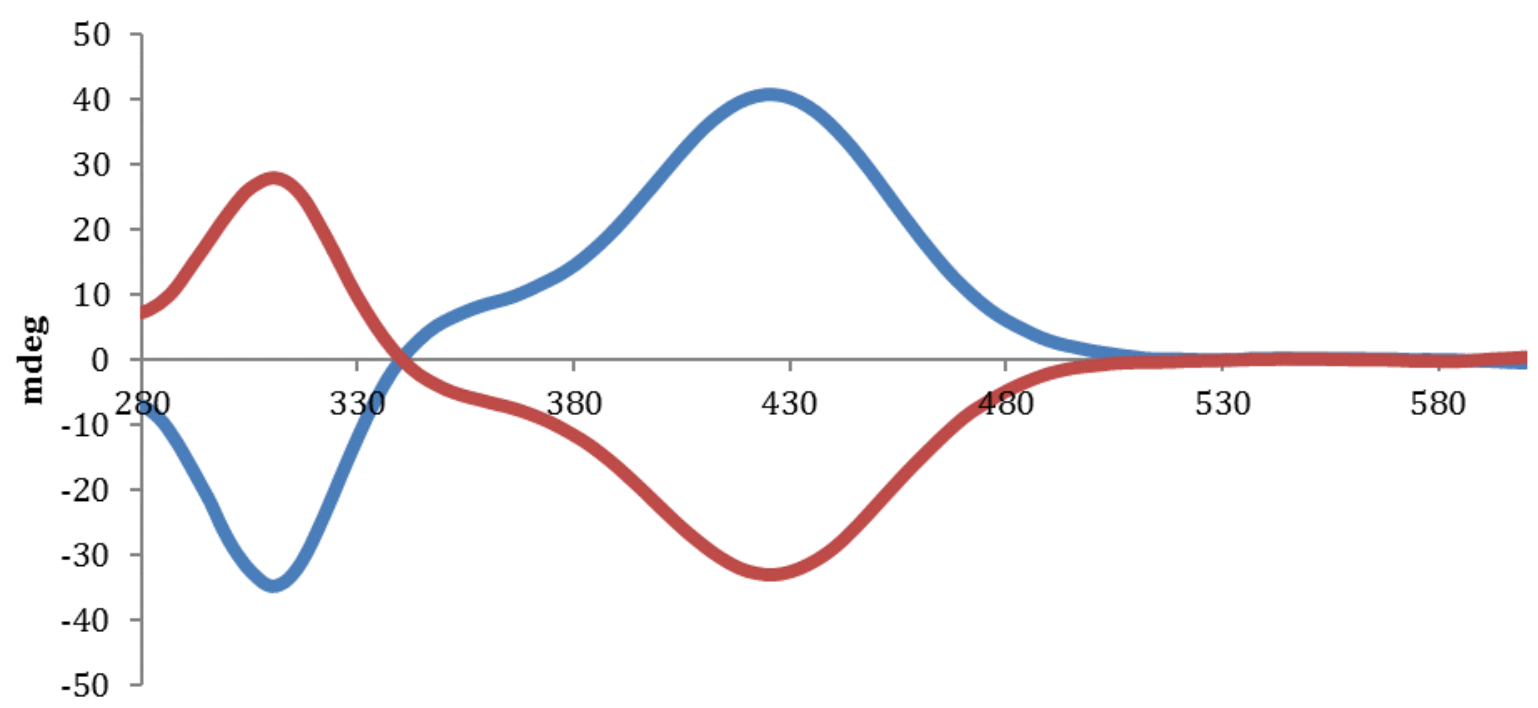


CD Spectra of the assembly obtained from 1, Pd(OAc) 2 and L-11 (blue) or D-11 (red)

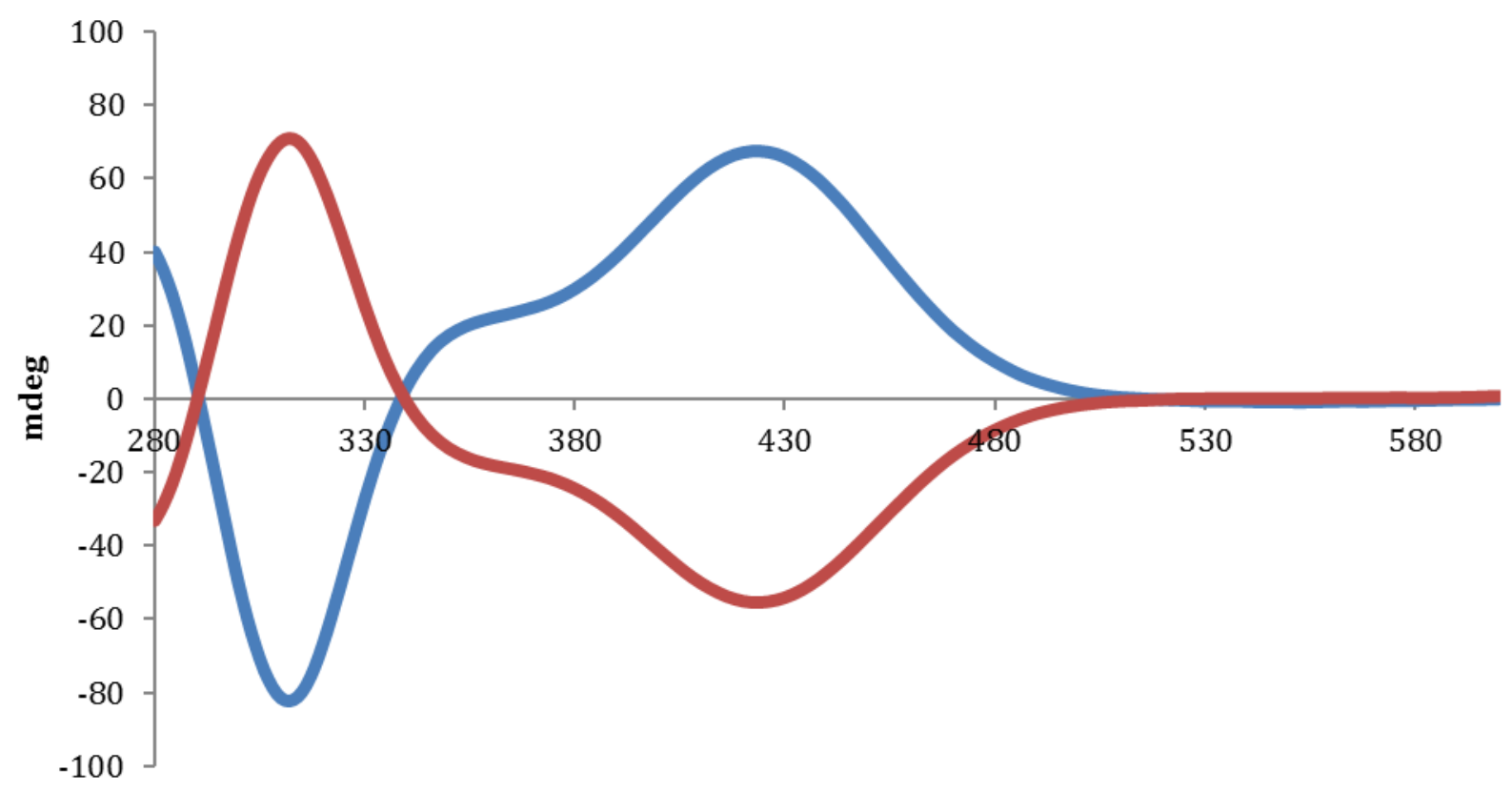

CD Spectra of the assembly obtained from 1, Pd(OAc) $)_{2}$ and L-12 (blue) or D-12 (red)

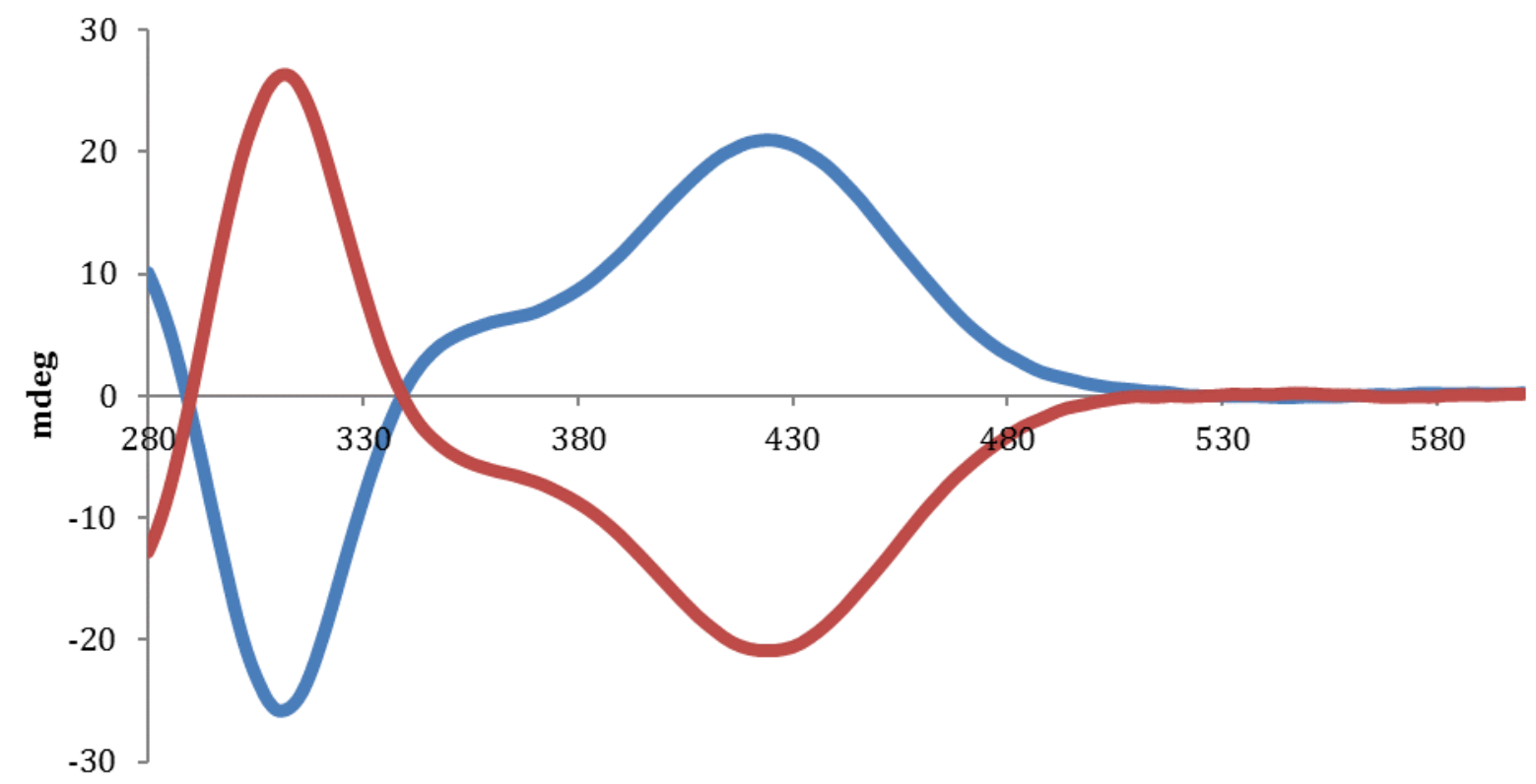


CD Spectra of the assembly obtained from 1, Pd(OAc) $)_{2}$ and L-13 (blue) or D-13 (red)

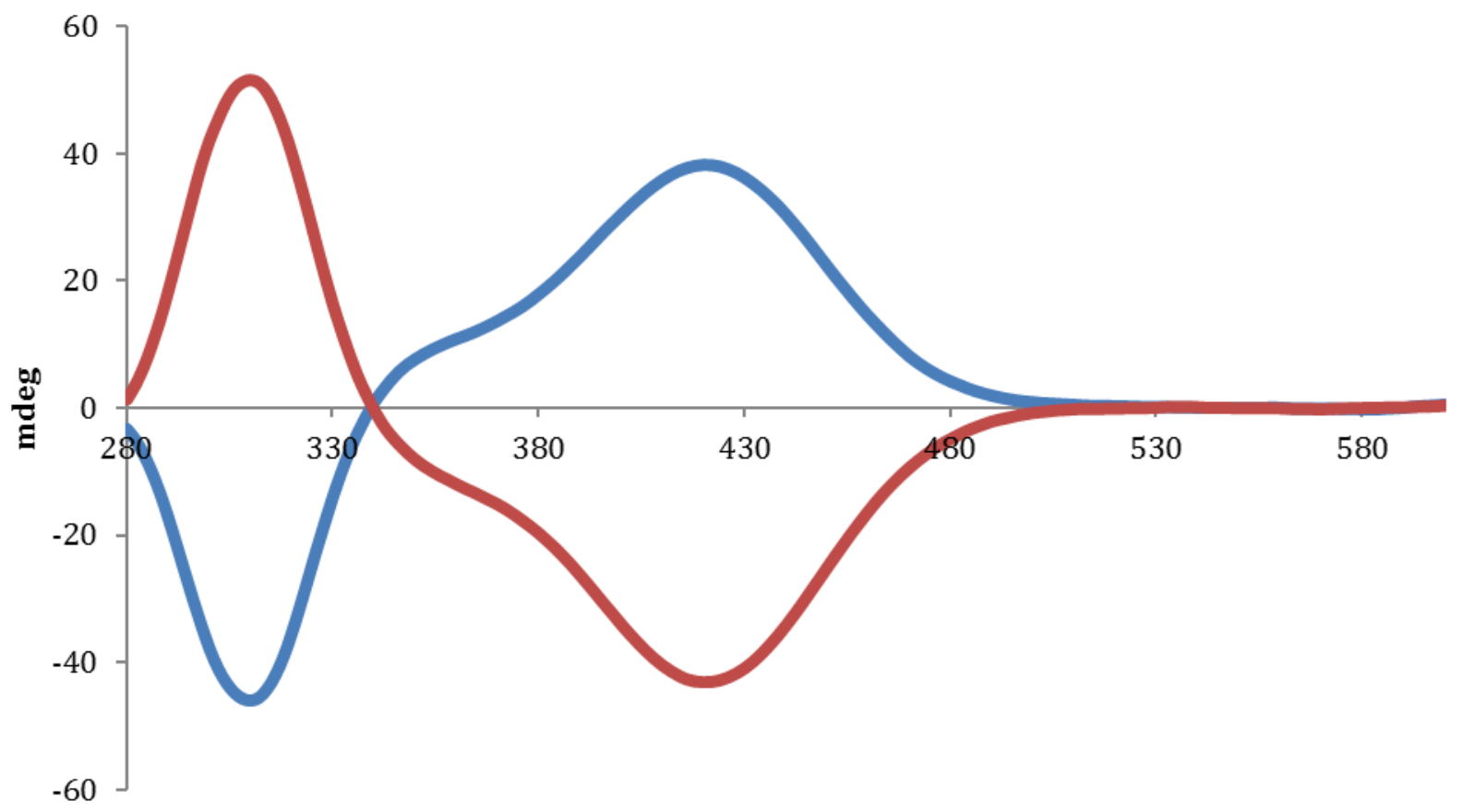

CD Spectra of the assembly obtained from 1, Pd(OAc) 2 and L-14 (blue) or D-14 (red)

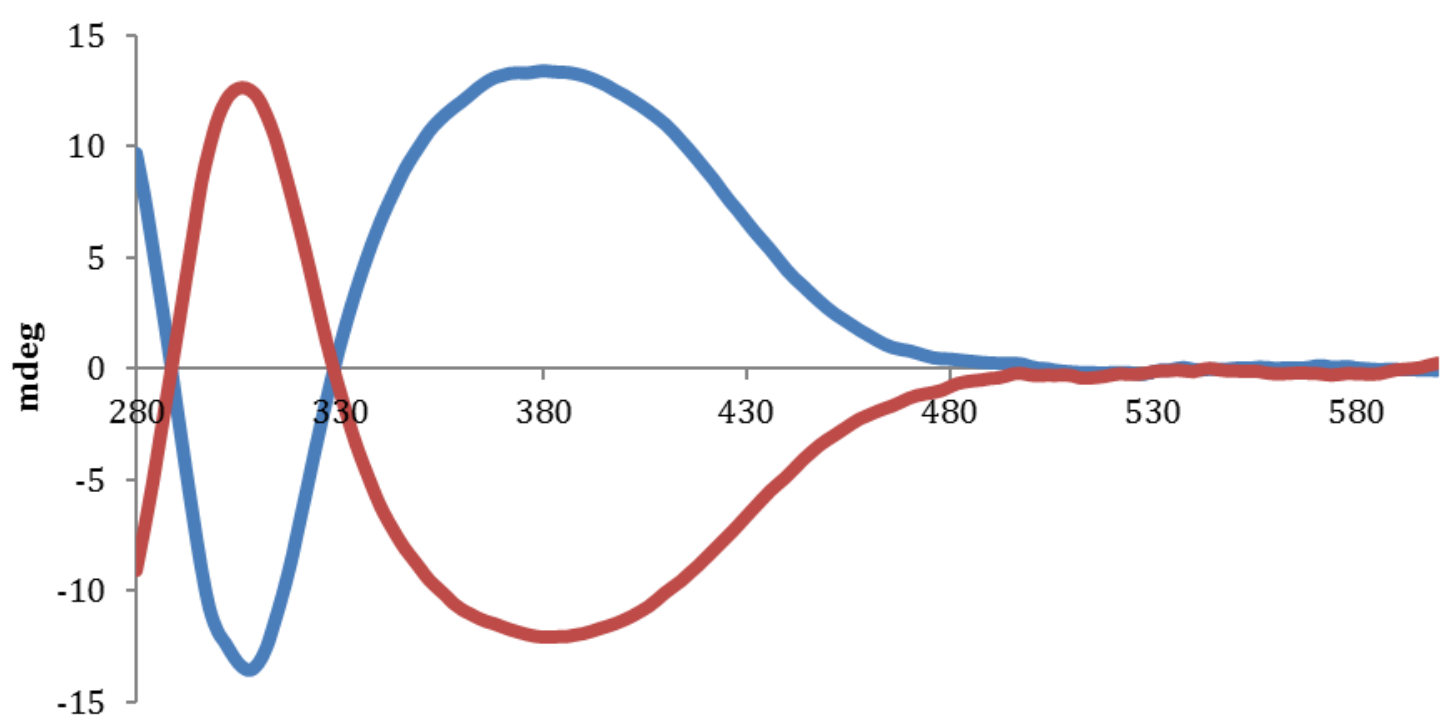


CD Spectra of the assembly obtained from 1, Pd(OAc) $)_{2}$ and L-15 (blue) or D-15 (red)

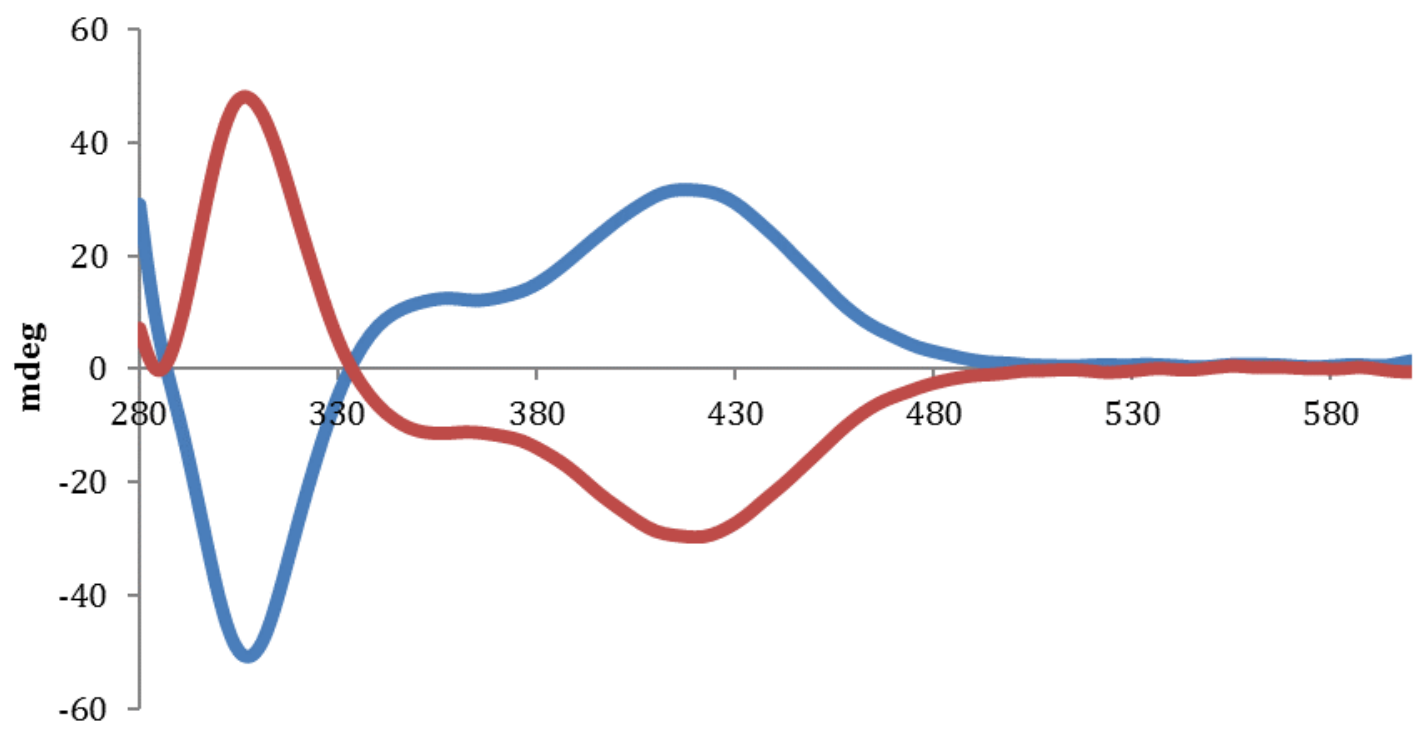

CD Spectra of the assembly obtained from 1, Pd(OAc) $)_{2}$ and L-16 (blue) or D-16 (red)

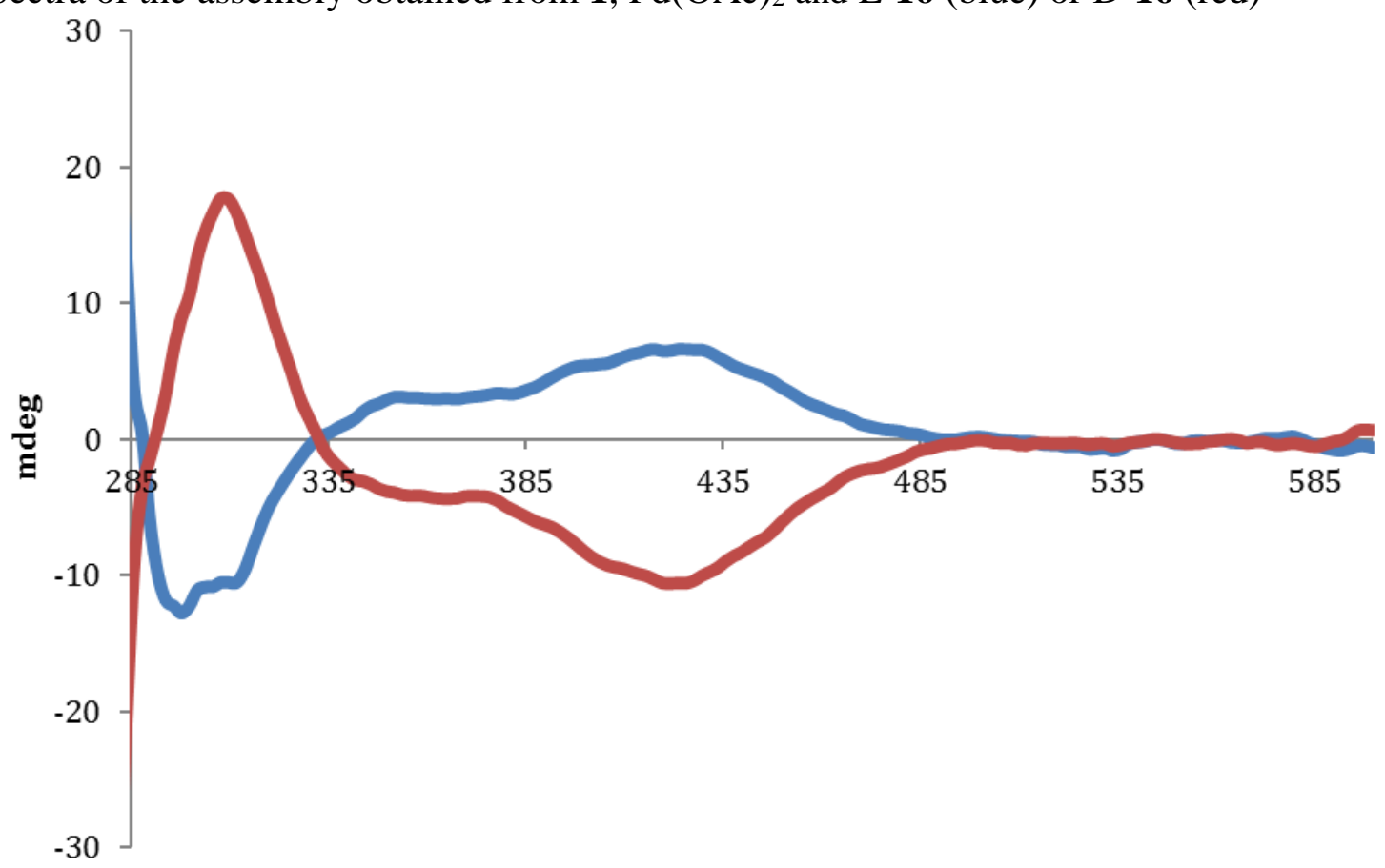


CD Spectra of the assembly obtained from 1, $\mathrm{Pd}(\mathrm{OAc})_{2}$ and $(R, S)-\mathbf{1 7}$ (blue) or $(S, R)-\mathbf{1 7}$ (red)

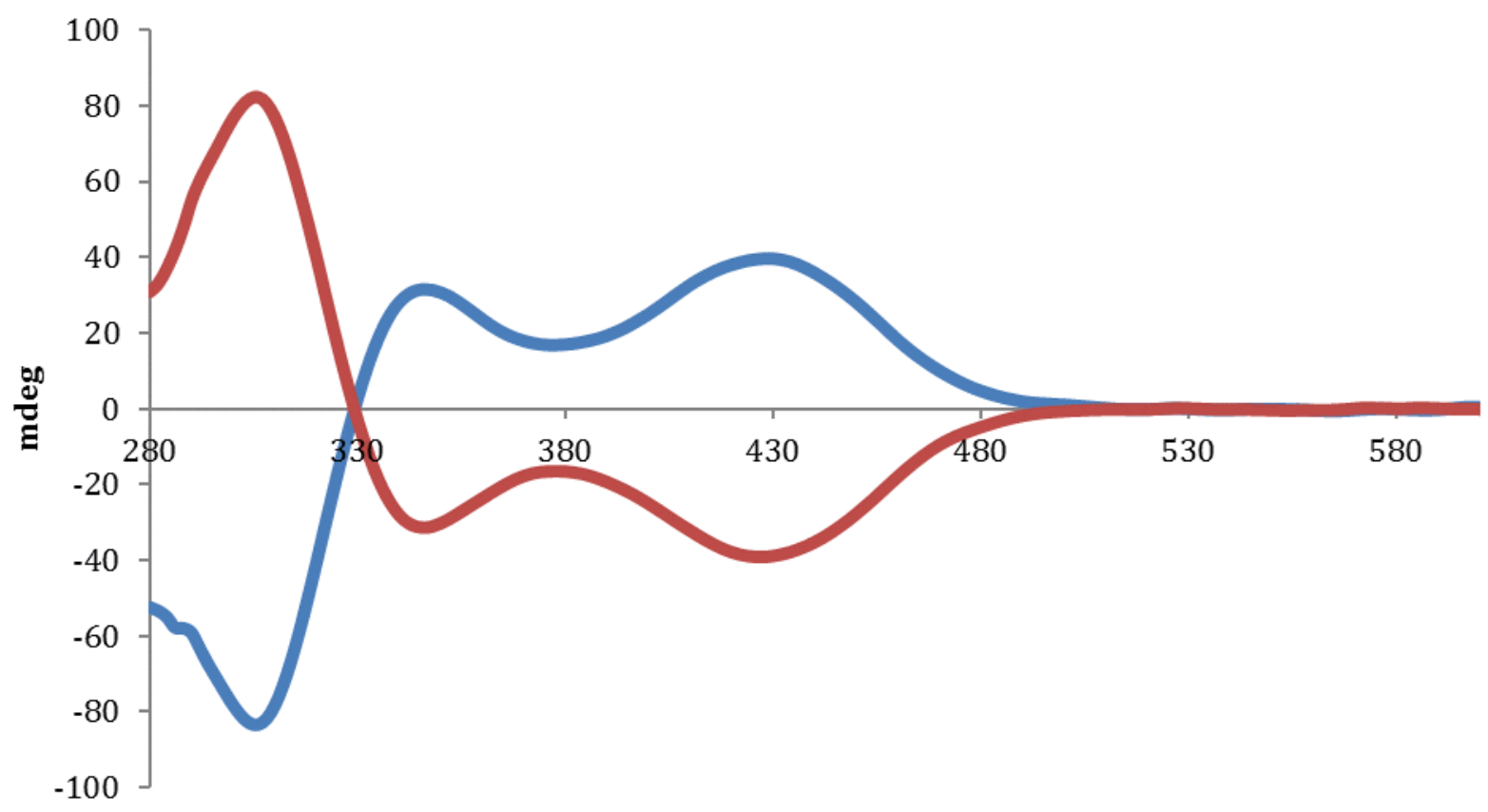

CD Spectra of the assembly obtained from $\mathbf{1}, \operatorname{Pd}(\mathrm{OAc})_{2}$ and $(R, S)-\mathbf{1 8}$ (blue) or $(S, R)-\mathbf{1 8}$ (red)

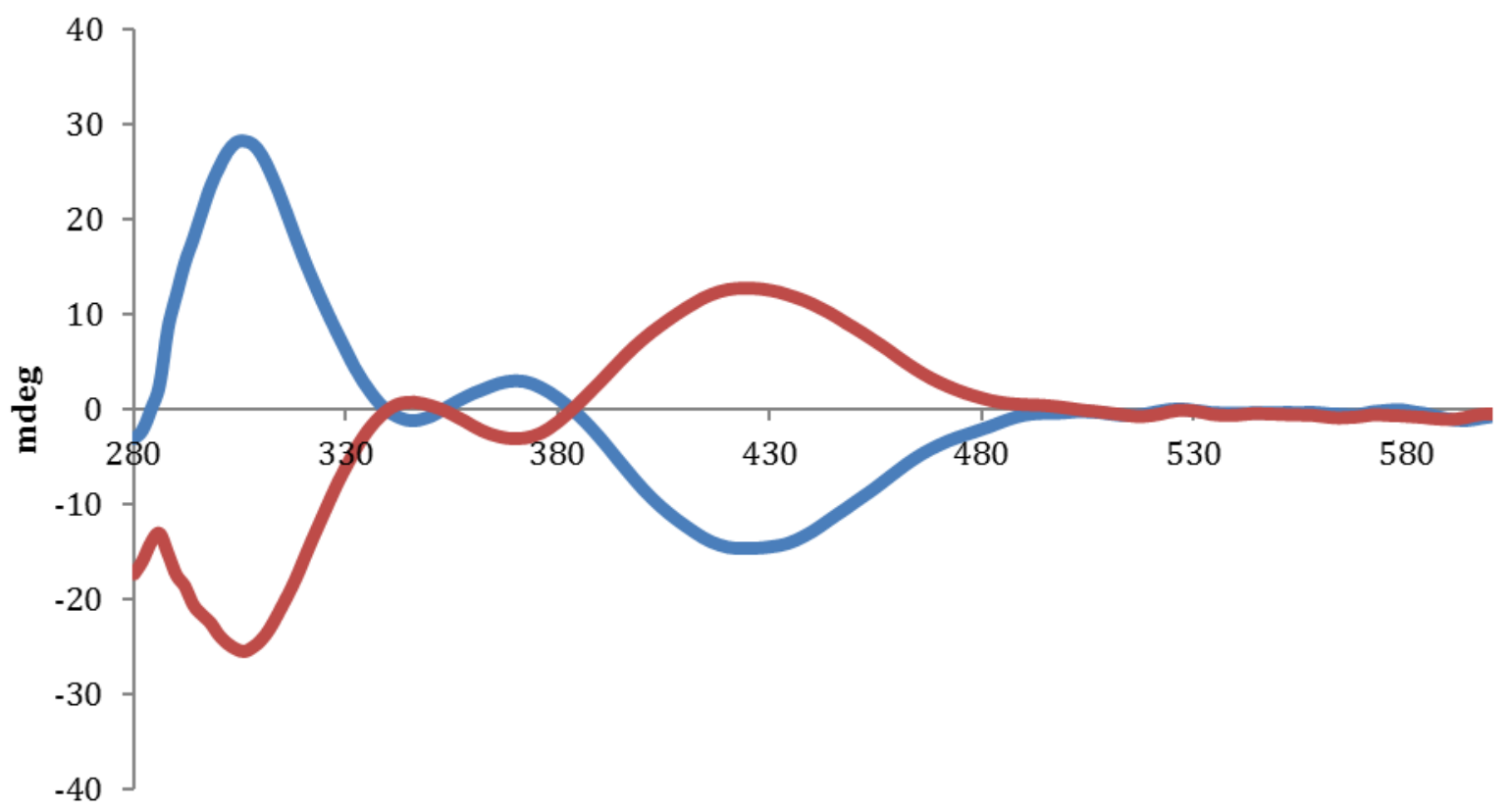


CD Spectra of the assembly obtained from 1, $\mathrm{Pd}(\mathrm{OAc})_{2}$ and $(R)-\mathbf{1 9}$ (blue) or $(S)-\mathbf{1 9}$ (red)

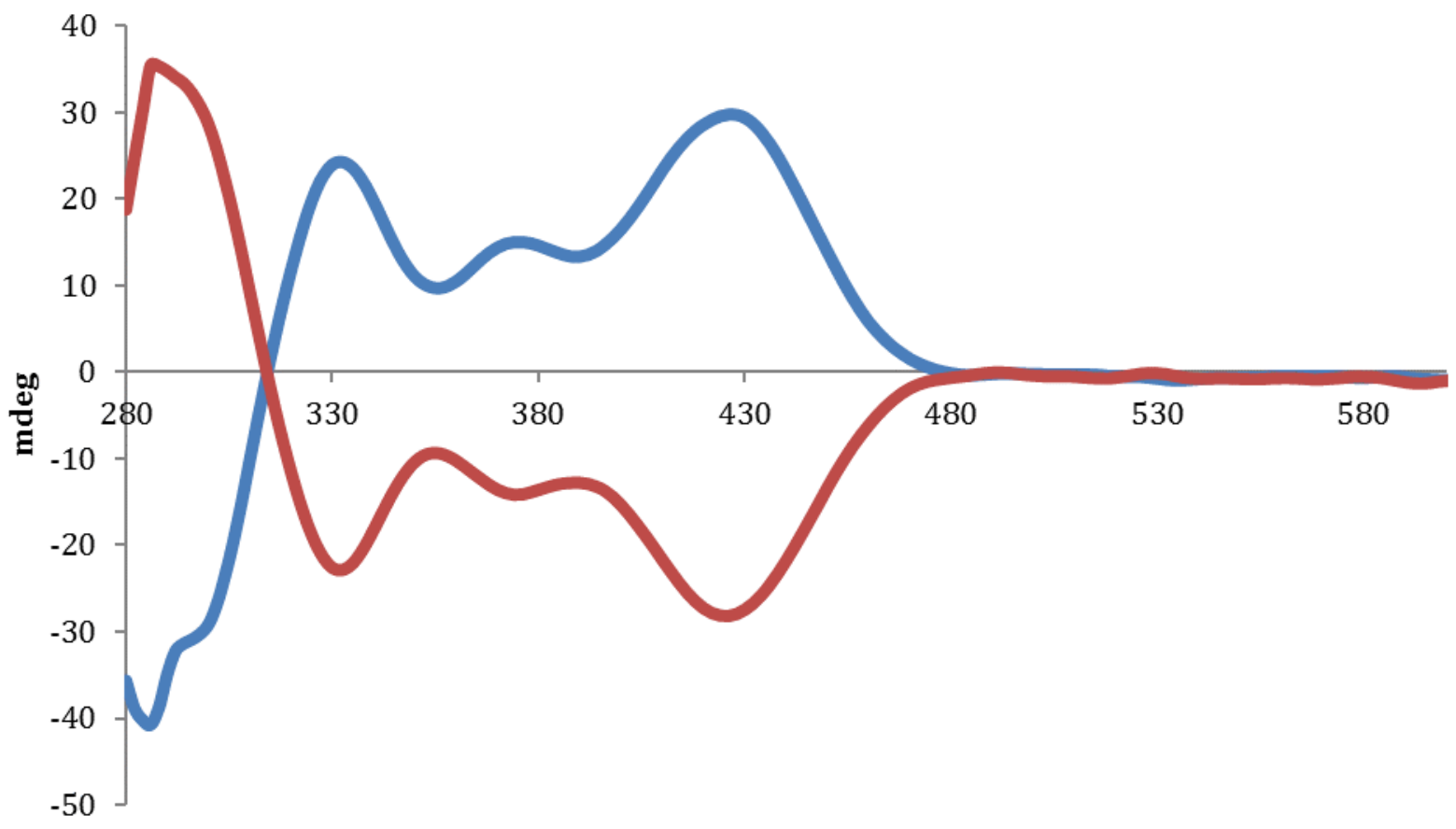

CD Spectra of the assembly obtained from 1, $\mathrm{Pd}(\mathrm{OAc})_{2}$ and $(R)-\mathbf{2 0}$ (blue) or $(S)$-20 (red)

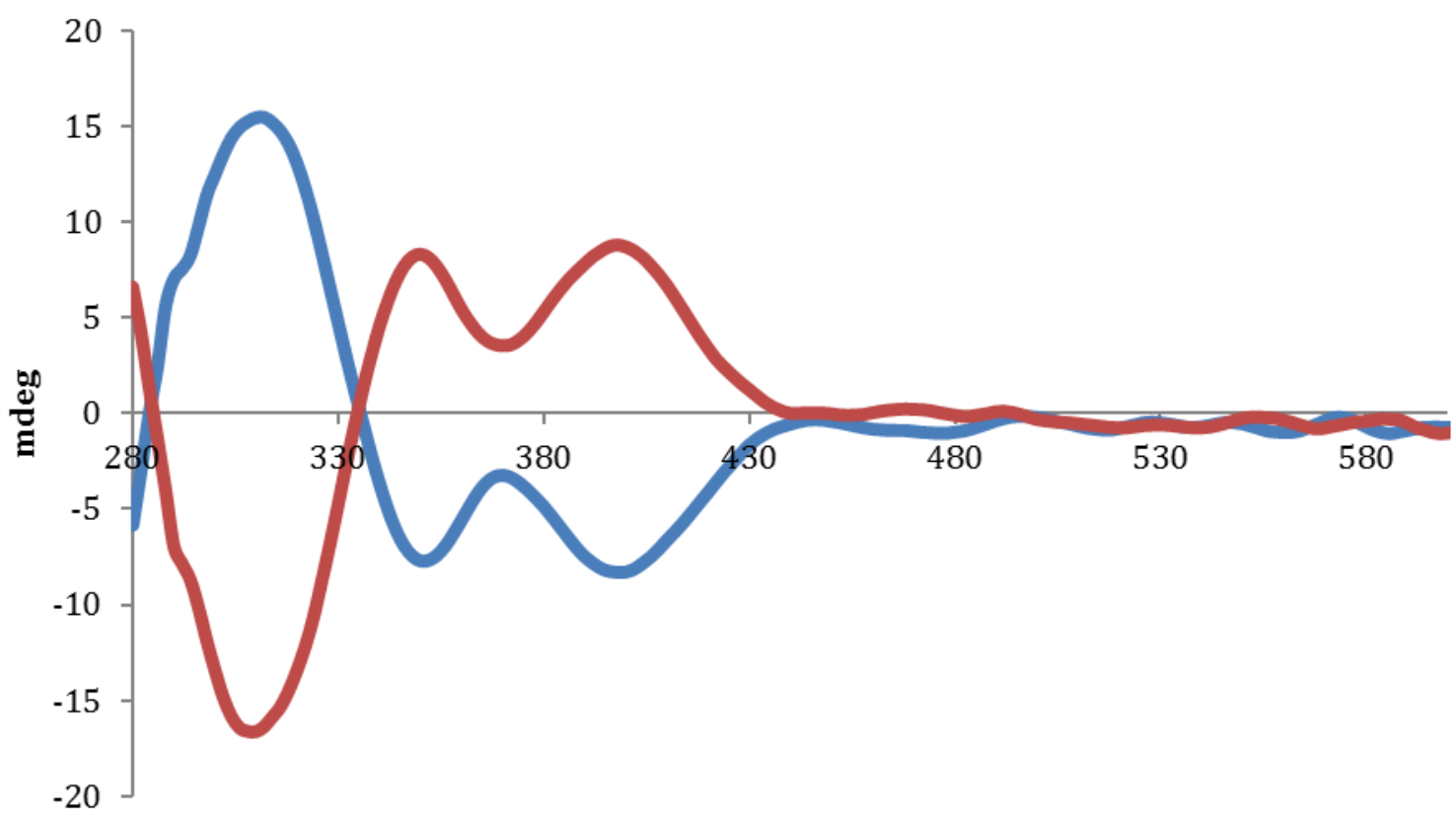


CD Spectra of the assembly obtained from 1, $\mathrm{Pd}(\mathrm{OAc})_{2}$ and $(R, R)-\mathbf{2 1}$ (blue) or $(S, S)-\mathbf{2 1}$ (red)

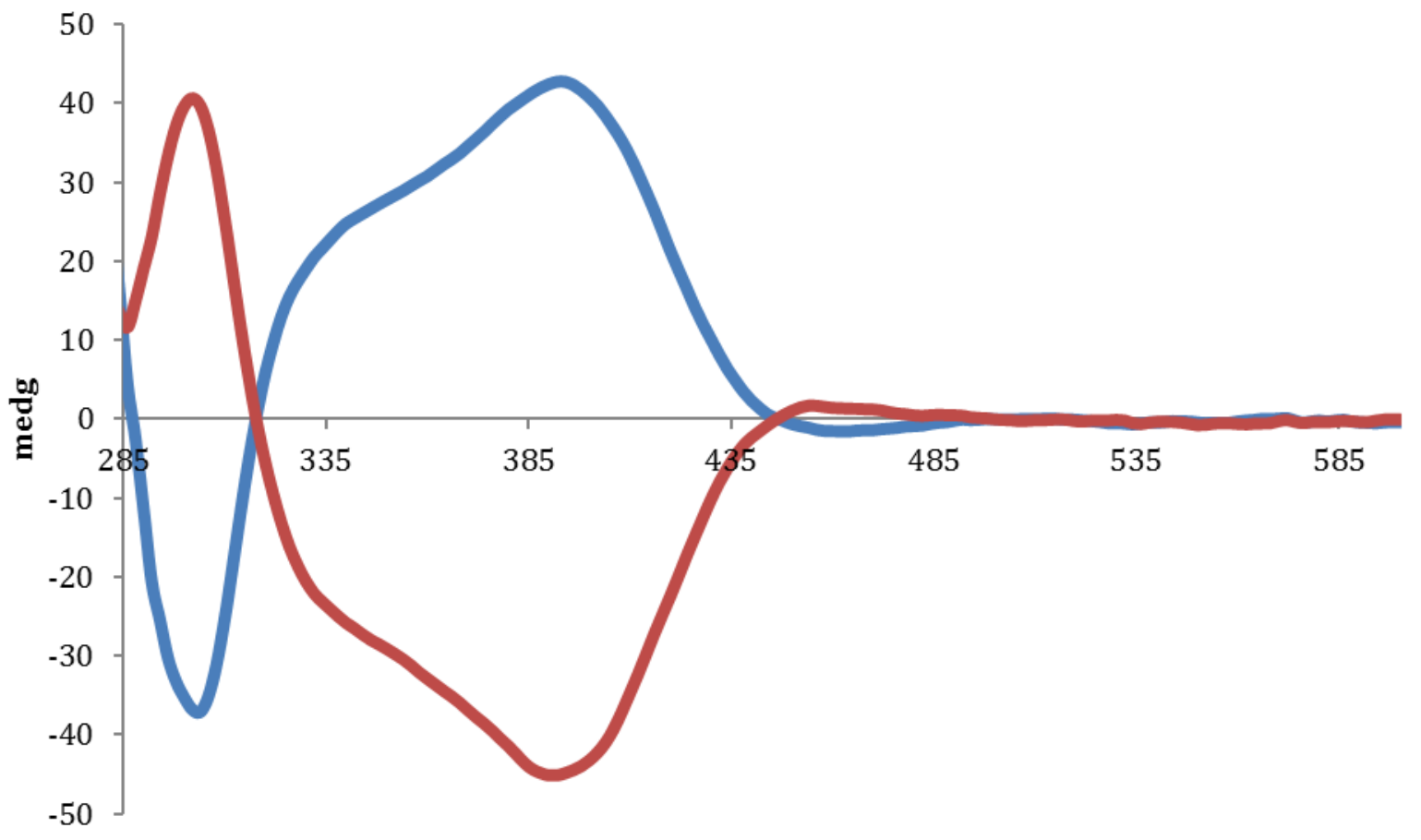

CD Spectra of the assembly obtained from $\mathbf{1}, \mathrm{Pd}(\mathrm{OAc})_{2}$ and $(R, R)-\mathbf{2 2}$ (blue) or $(S, S)-\mathbf{2 2}$ (red)

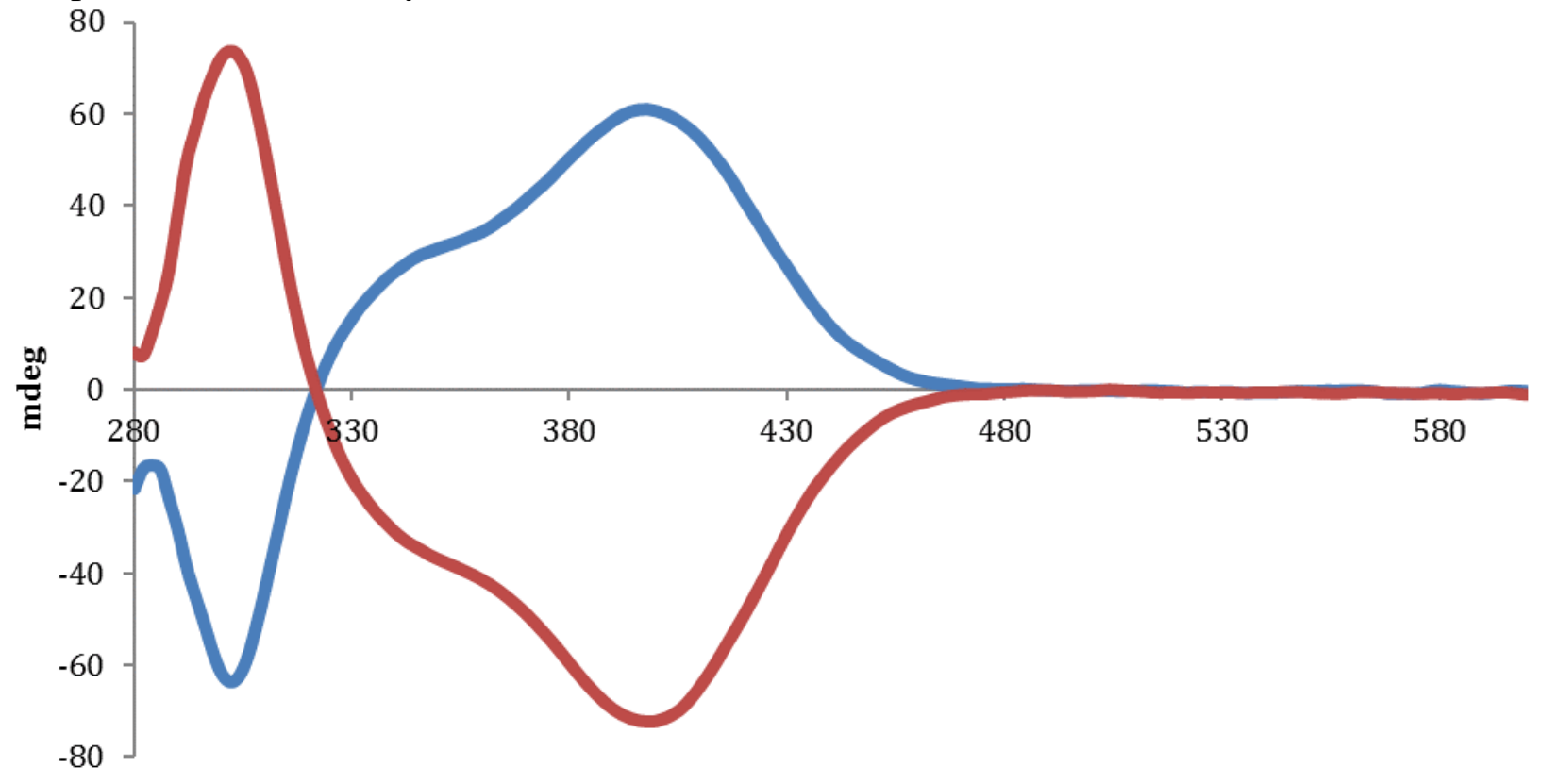


CD Spectra of the assembly obtained from $\mathbf{1}, \mathrm{Pd}(\mathrm{OAc})_{2}$ and $(R)-\mathbf{2 3}$ (blue) or $(S)-\mathbf{2 3}$ (red)

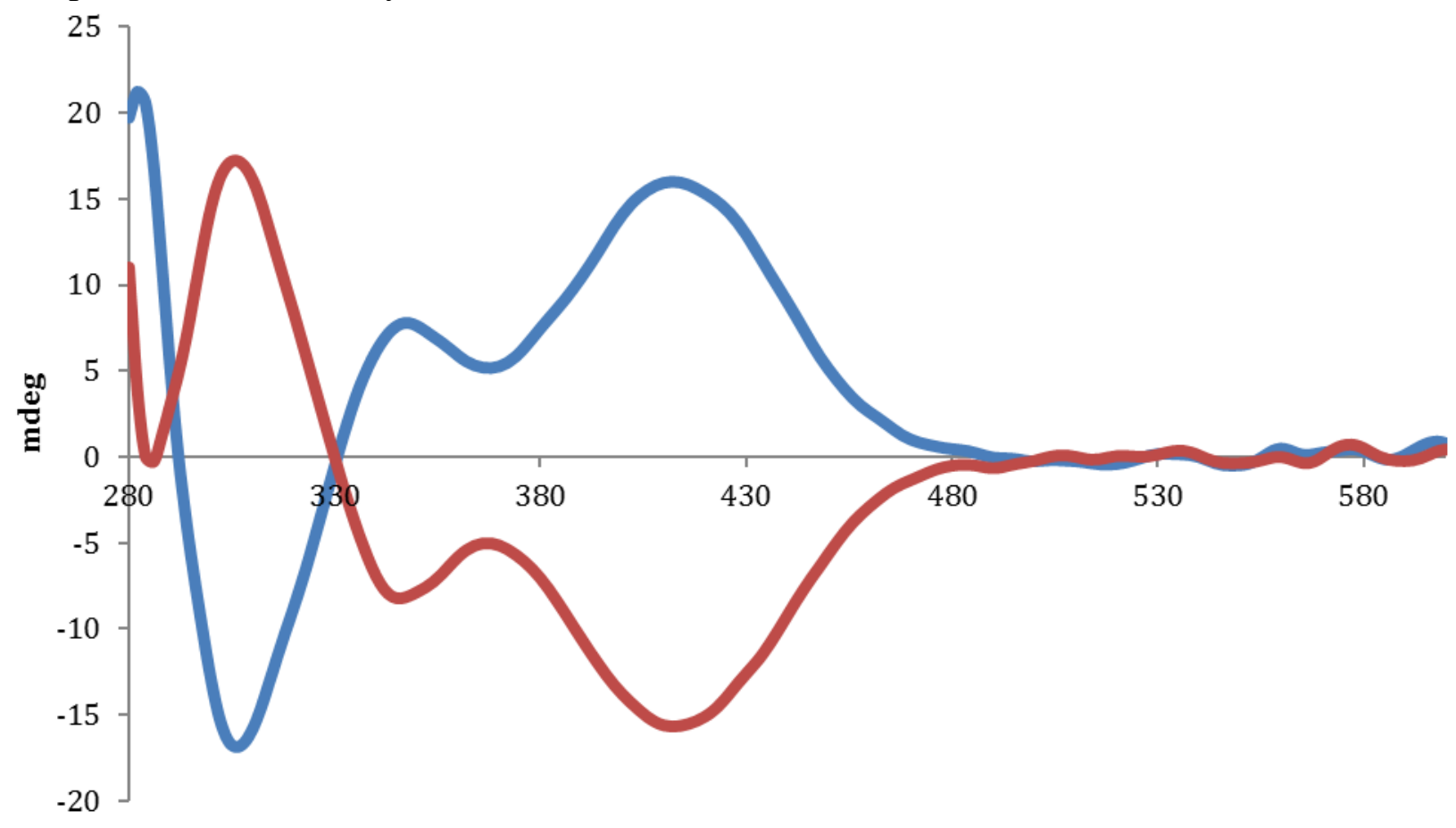

CD Spectra of the assembly obtained from 1, $\mathrm{Pd}(\mathrm{OAc})_{2}$ and $(R)-\mathbf{2 4}$ (blue) or $(S)$-24 (red)

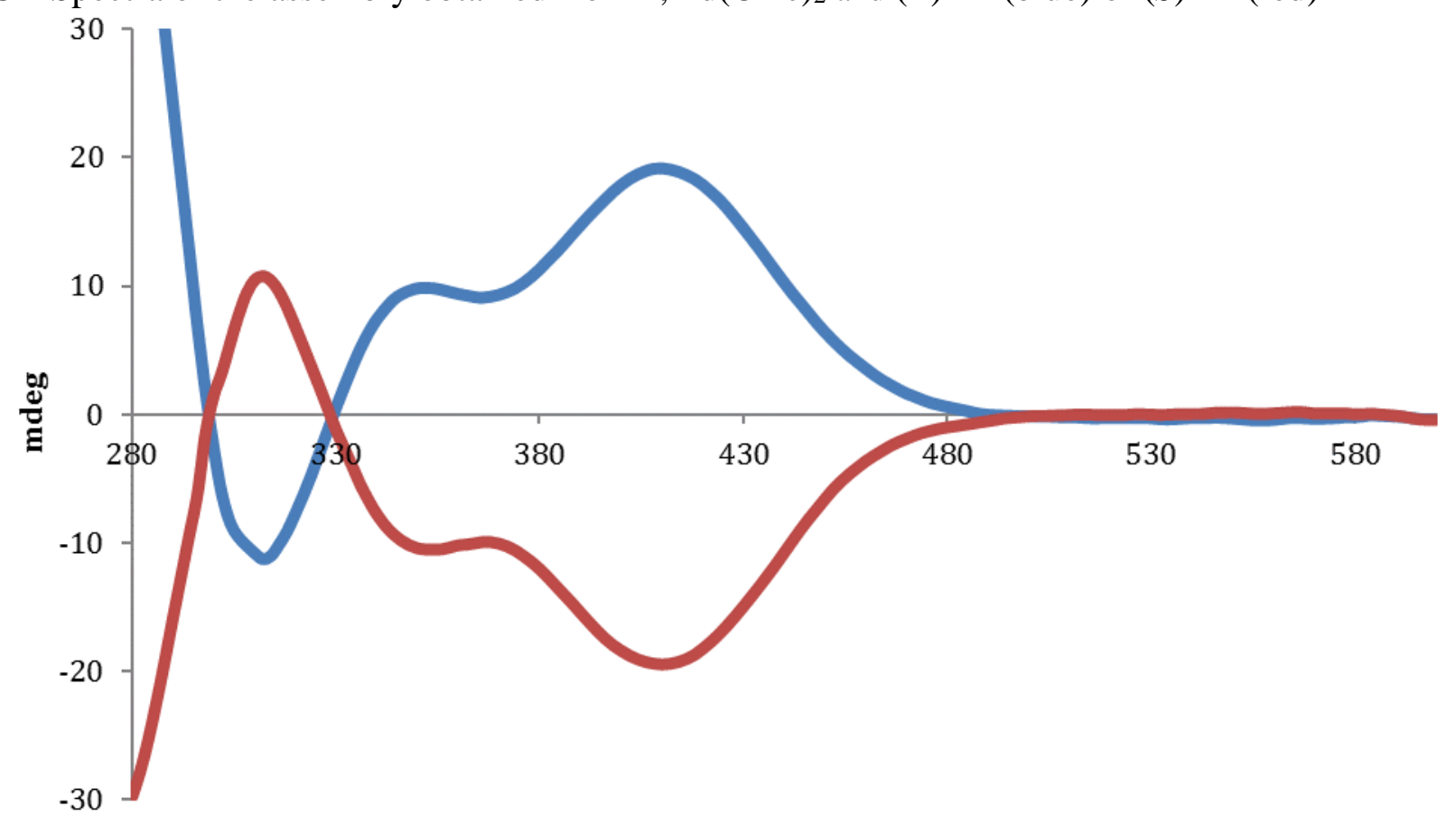


CD Spectra of the assembly obtained from 1, $\mathrm{Pd}(\mathrm{OAc})_{2}$ and $(R)-\mathbf{2 5}$ (blue) or $(S)-\mathbf{2 5}$ (red)

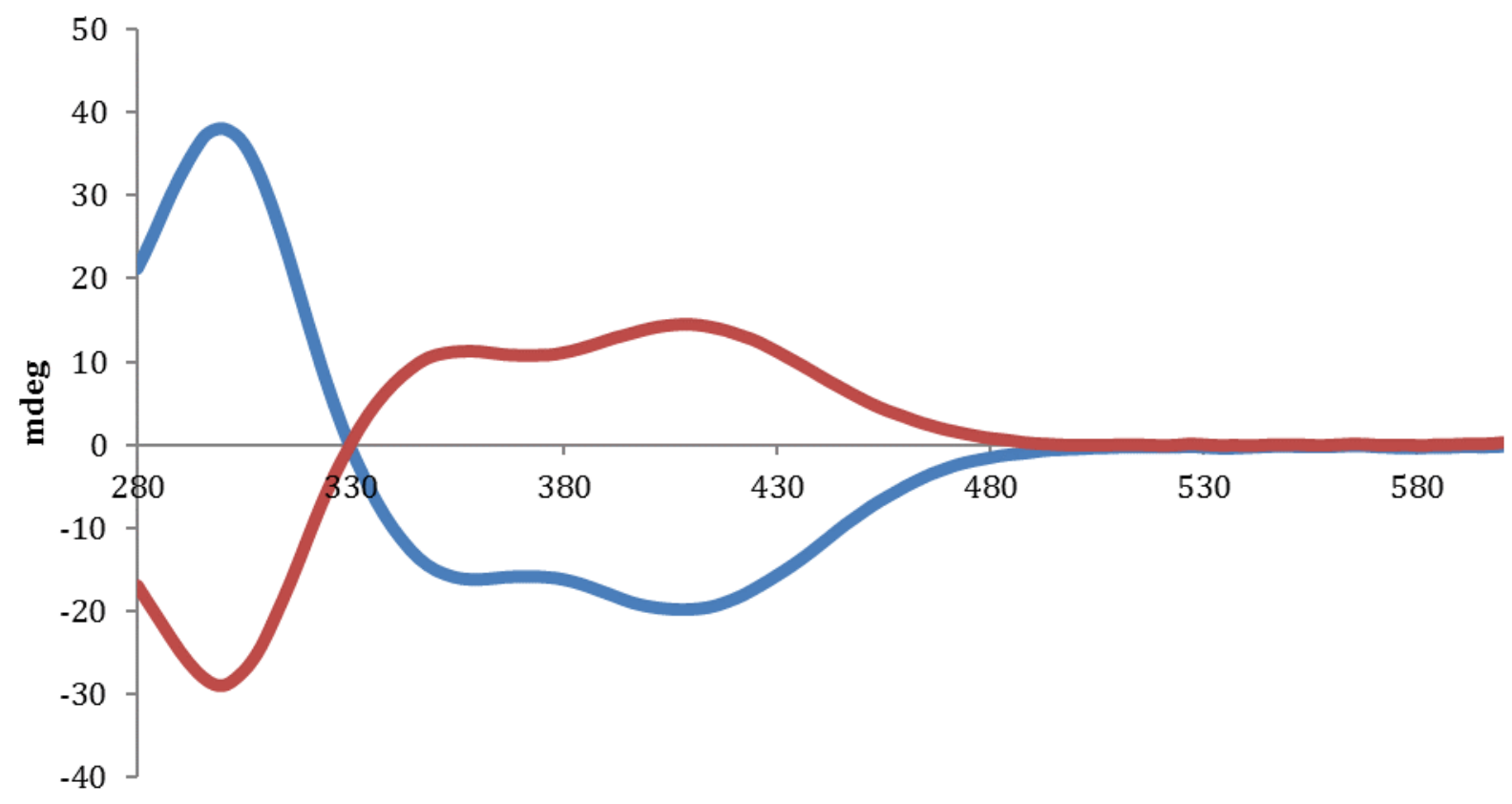




\section{Mechanistic study of the assembly process}

\subsection{MS analysis}

ESI-MS of the complex formed from 1, Pd(OAc) 2 , and L-5 (metal complex $=660 \mathrm{~m} / \mathrm{z}$ ).

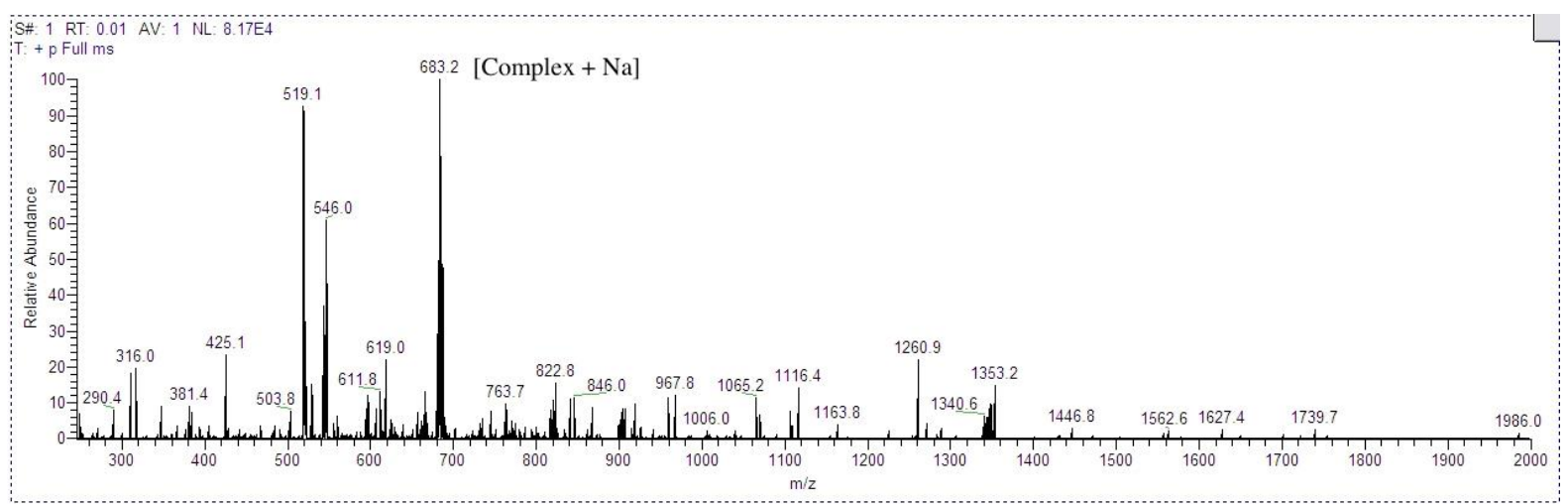

The complex was formed by mixing $1\left(0.005 \mathrm{mmol}\right.$ in $0.5 \mathrm{~mL}$ of $\left.\mathrm{CHCl}_{3}\right), \mathrm{L}-5(0.01 \mathrm{~mL}, 0.5$ $\mathrm{M} \mathrm{MeOH} / \mathrm{TBAOH}, 1: 1)$ and $\mathrm{Pd}(\mathrm{OAc})_{2}\left(0.02 \mathrm{~mL}, 0.25 \mathrm{M} \mathrm{CHCl}_{3}\right)$. The mixture was stirred for 30 minutes prior to electrospray mass spectrometry (positive ion mode) analysis.

ESI-MS of the complex formed from 1, $\mathrm{Pd}(\mathrm{OAc})_{2}$, and L-18 (metal complex $=644 \mathrm{~m} / \mathrm{z}$ ).

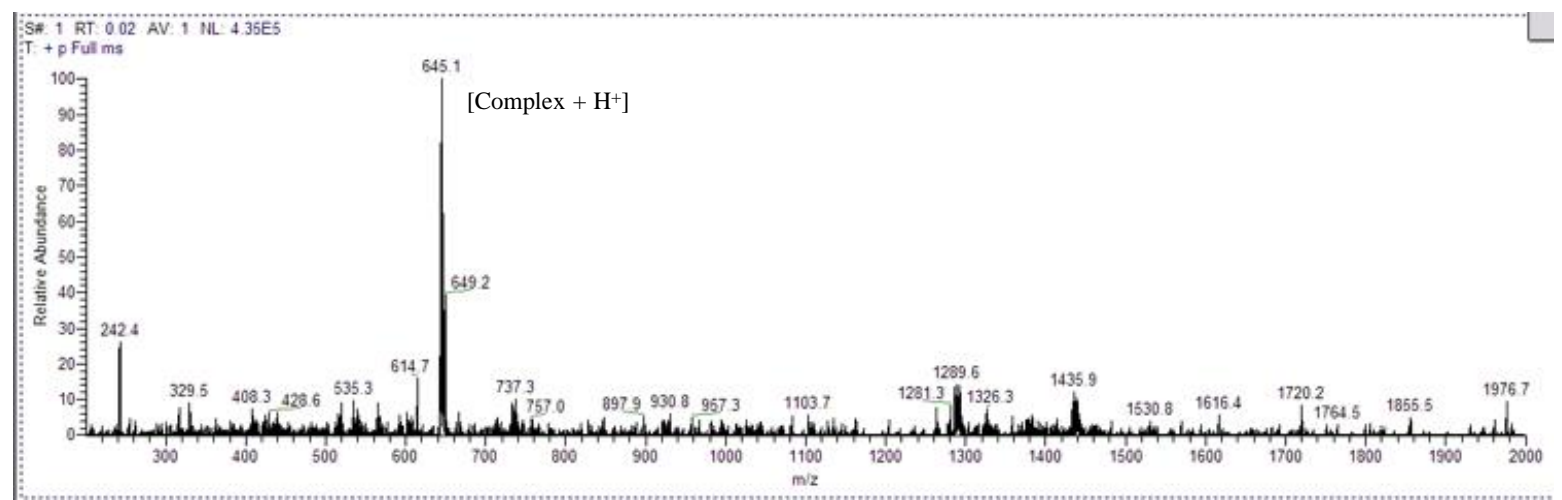

The complex was formed by mixing $1\left(0.005 \mathrm{mmol}\right.$ in $0.5 \mathrm{~mL}$ of $\left.\mathrm{CHCl}_{3}\right), \mathrm{L}-18(0.01 \mathrm{~mL}, 0.5$ $\mathrm{M} \mathrm{MeOH} / \mathrm{TBAOH}, 1: 1)$ and $\mathrm{Pd}(\mathrm{OAc})_{2}\left(0.02 \mathrm{~mL}, 0.25 \mathrm{M} \mathrm{CHCl}_{3}\right)$. The mixture was stirred for 30 minutes prior to electrospray mass spectrometry (positive ion mode) analysis. 
ESI-MS of the complex formed from 1, Pd(OAc) 2 , and L-20 (metal complex $=570 \mathrm{~m} / \mathrm{z}$ ).

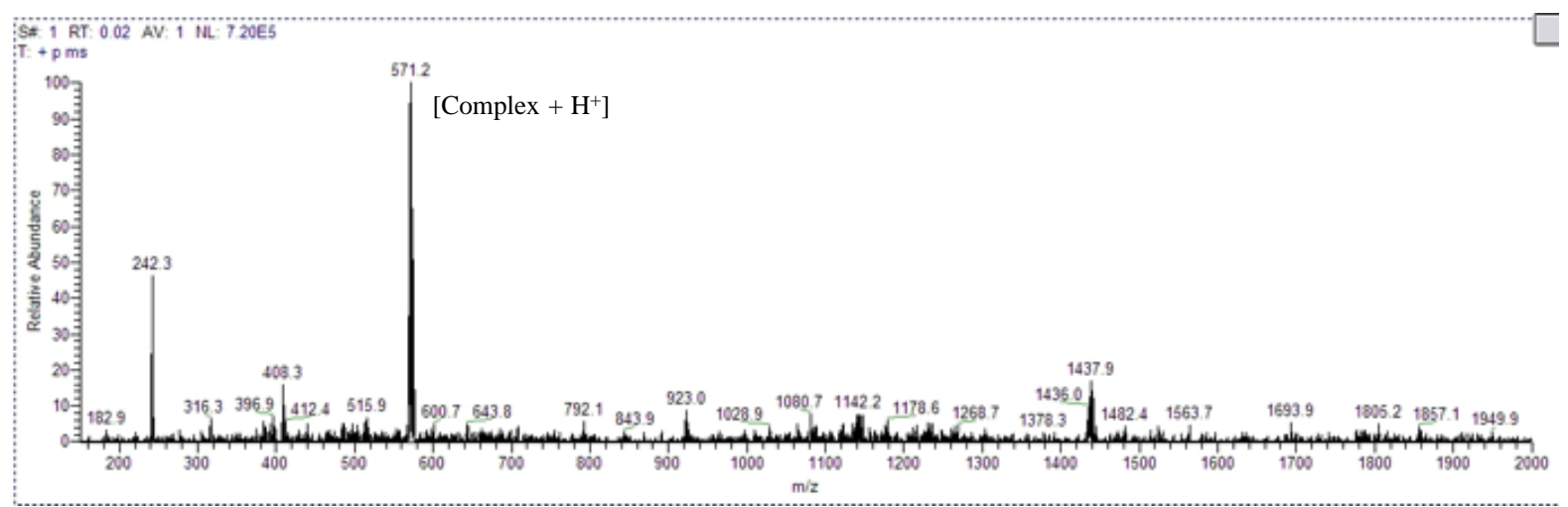

The complex was formed by mixing $1\left(0.005 \mathrm{mmol}\right.$ in $0.5 \mathrm{~mL}$ of $\left.\mathrm{CHCl}_{3}\right), \mathrm{L}-20(0.01 \mathrm{~mL}, 0.5$ $\mathrm{M} \mathrm{MeOH} / \mathrm{TBAOH}, 1: 1)$ and $\mathrm{Pd}(\mathrm{OAc})_{2}\left(0.2 \mathrm{~mL}, 0.25 \mathrm{M} \mathrm{CHCl}_{3}\right)$. The mixture was stirred for 30 minutes prior to electrospray mass spectrometry (positive ion mode) analysis.

ESI-MS of the complex formed from 1, $\mathrm{Pd}(\mathrm{OAc})_{2}$, and L-23 (metal complex $=617 \mathrm{~m} / \mathrm{z}$ ).

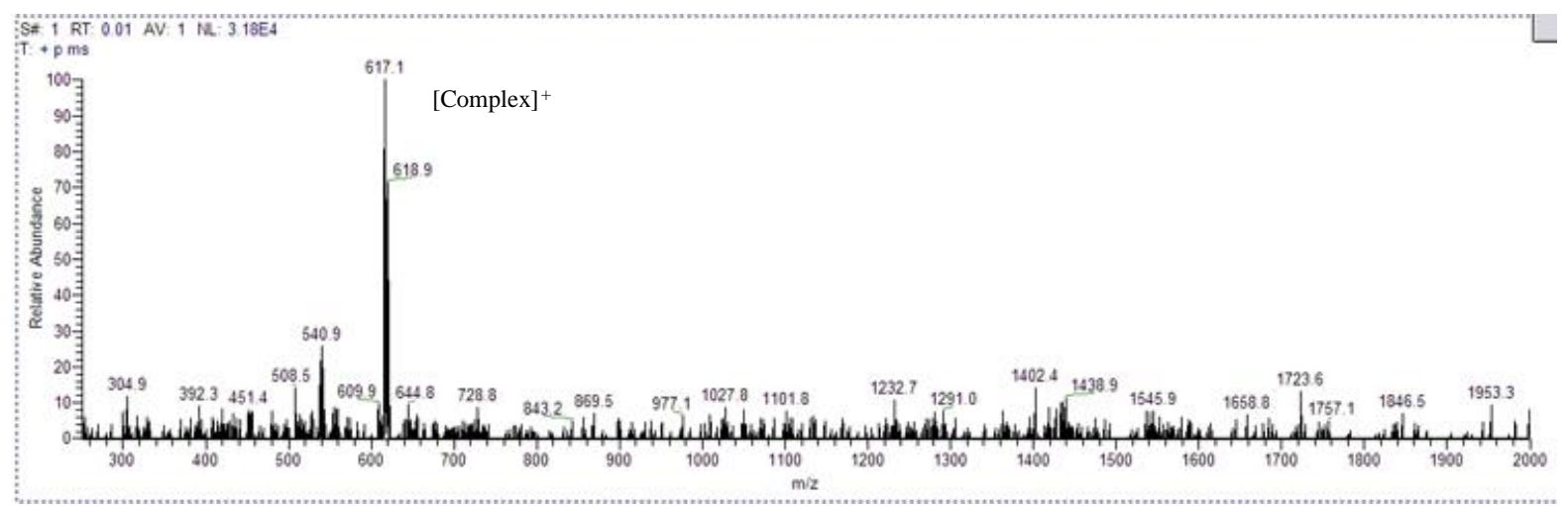

The complex was formed by mixing $1\left(0.005 \mathrm{mmol}\right.$ in $0.5 \mathrm{~mL}$ of $\left.\mathrm{CHCl}_{3}\right), \mathrm{L}-23(0.01 \mathrm{~mL}, 0.5$ $\mathrm{M} \mathrm{MeOH} / \mathrm{TBAOH}, 1: 1)$ and $\mathrm{Pd}(\mathrm{OAc})_{2}\left(0.2 \mathrm{~mL}, 0.25 \mathrm{M} \mathrm{CHCl}_{3}\right)$. The mixture was stirred for 30 minutes prior to electrospray mass spectrometry (positive ion mode) analysis. 


\subsection{NMR analysis}

${ }^{31} \mathrm{P}$ NMR studies showed quantitative imine formation and complex formation with $\mathrm{CDCl}_{3}$ used as solvent and triethyl phosphate $(\delta=0 \mathrm{ppm})$ used as an internal standard. NMR spectra were obtained after 30 minutes of mixing at $25^{\circ} \mathrm{C}$ with a sample concentration of $0.01 \mathrm{M}$.

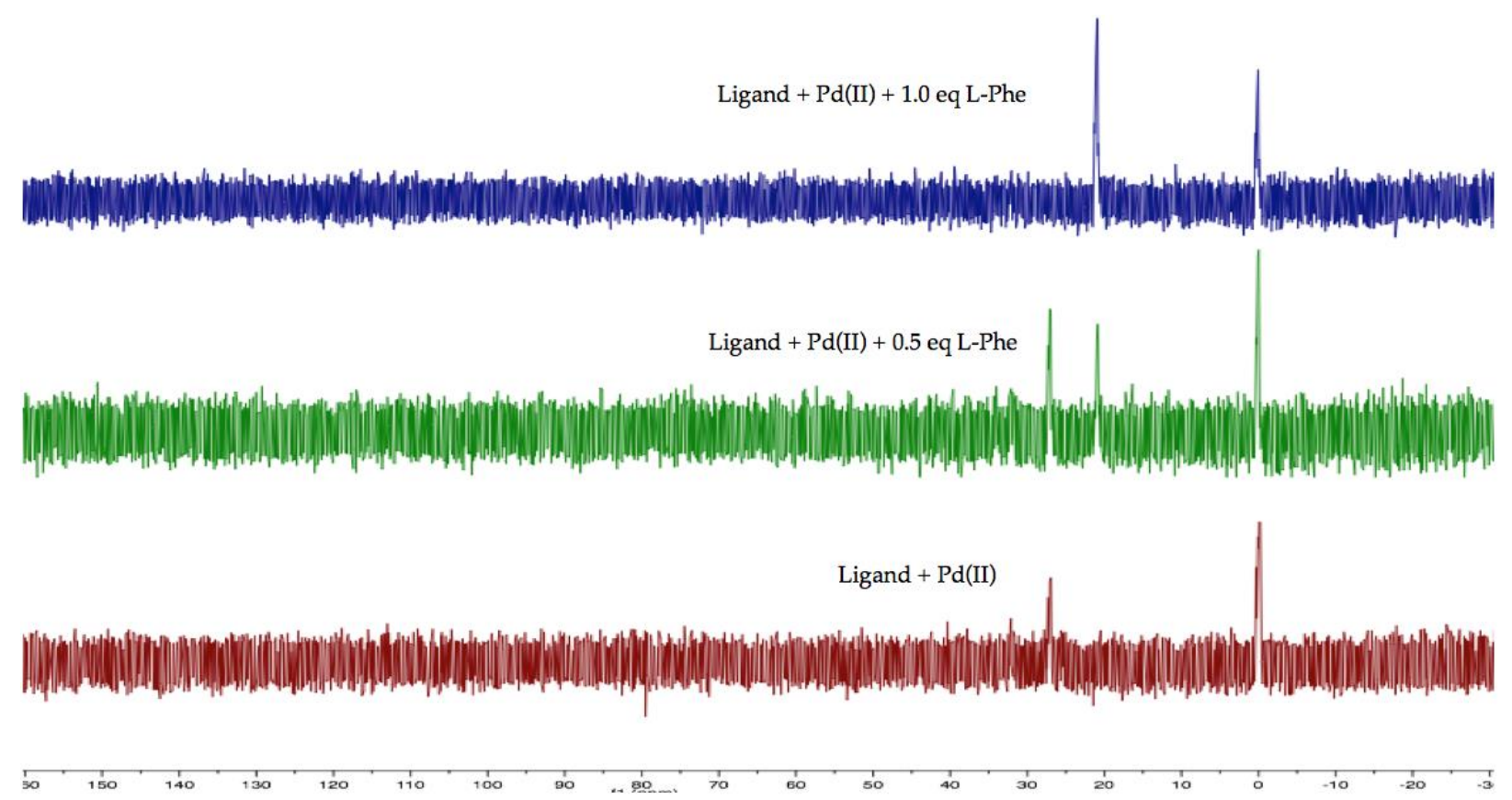

The complex assembly was investigated by ${ }^{1} \mathrm{H}$ NMR spectroscopy. The disappearance of the formyl peak ( 9.9 ppm) and amide peak ( 11.1 ppm) of $\mathbf{1}$ was observed five minutes after addition of $\mathrm{Pd}(\mathrm{OAc})_{2}$ and $\mathbf{5}$. Attempts to isolate the $\mathrm{Pd}$ assemblies derived from amino acids, amino alcohols, and amines by crystallization or chromatographic purification on silica gel were unsuccessful. A small amount of the assembly derived from L-5 was obtained by column chromatography on alumina using $\mathrm{CH}_{2} \mathrm{Cl}_{2}: \mathrm{MeOH}(9: 1)$ as mobile phase. The ${ }^{1} \mathrm{H}$ NMR spectrum clearly shows the expected imine signal and the aliphatic Phe signals in addition to the aromatic protons from the ligand and Phe. 
Ligand 1
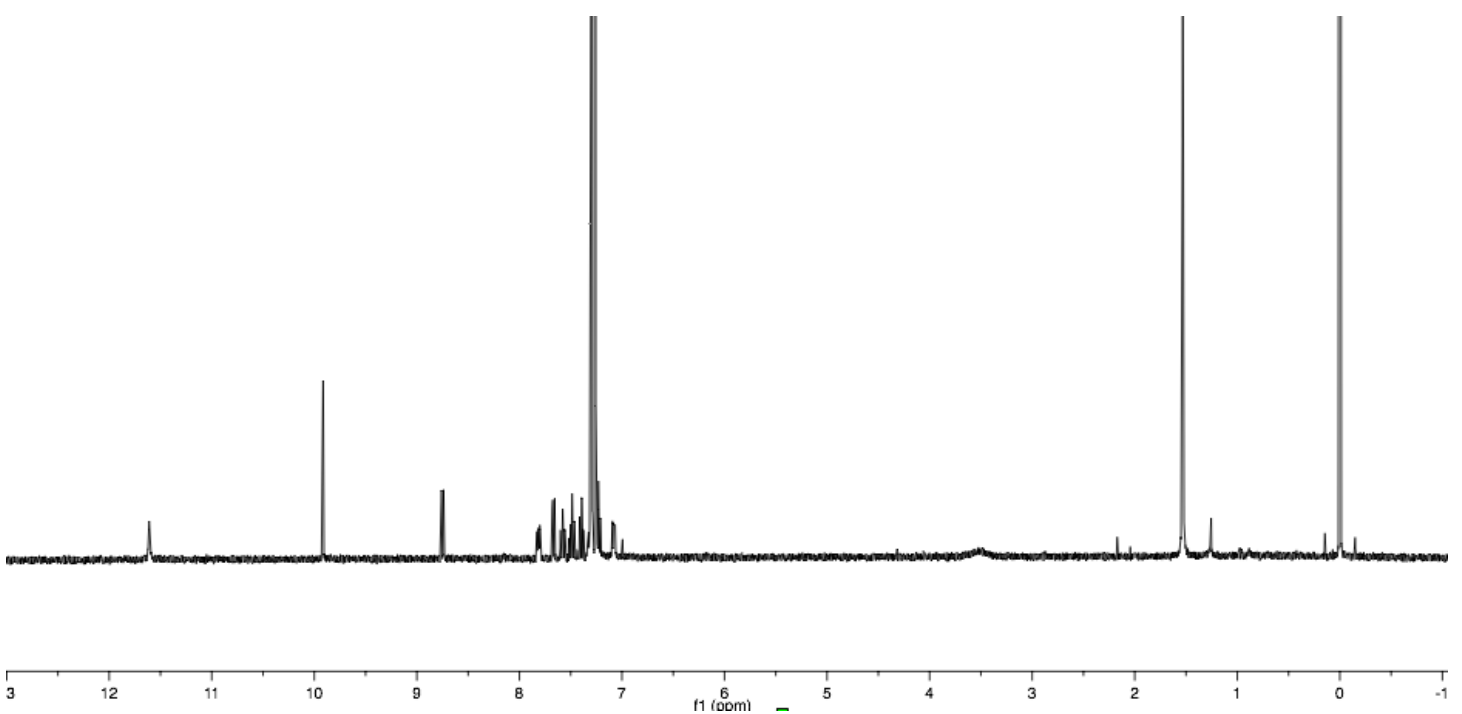

Ligand $1+\operatorname{Pd}(\mathrm{II})+\mathrm{L}-5$

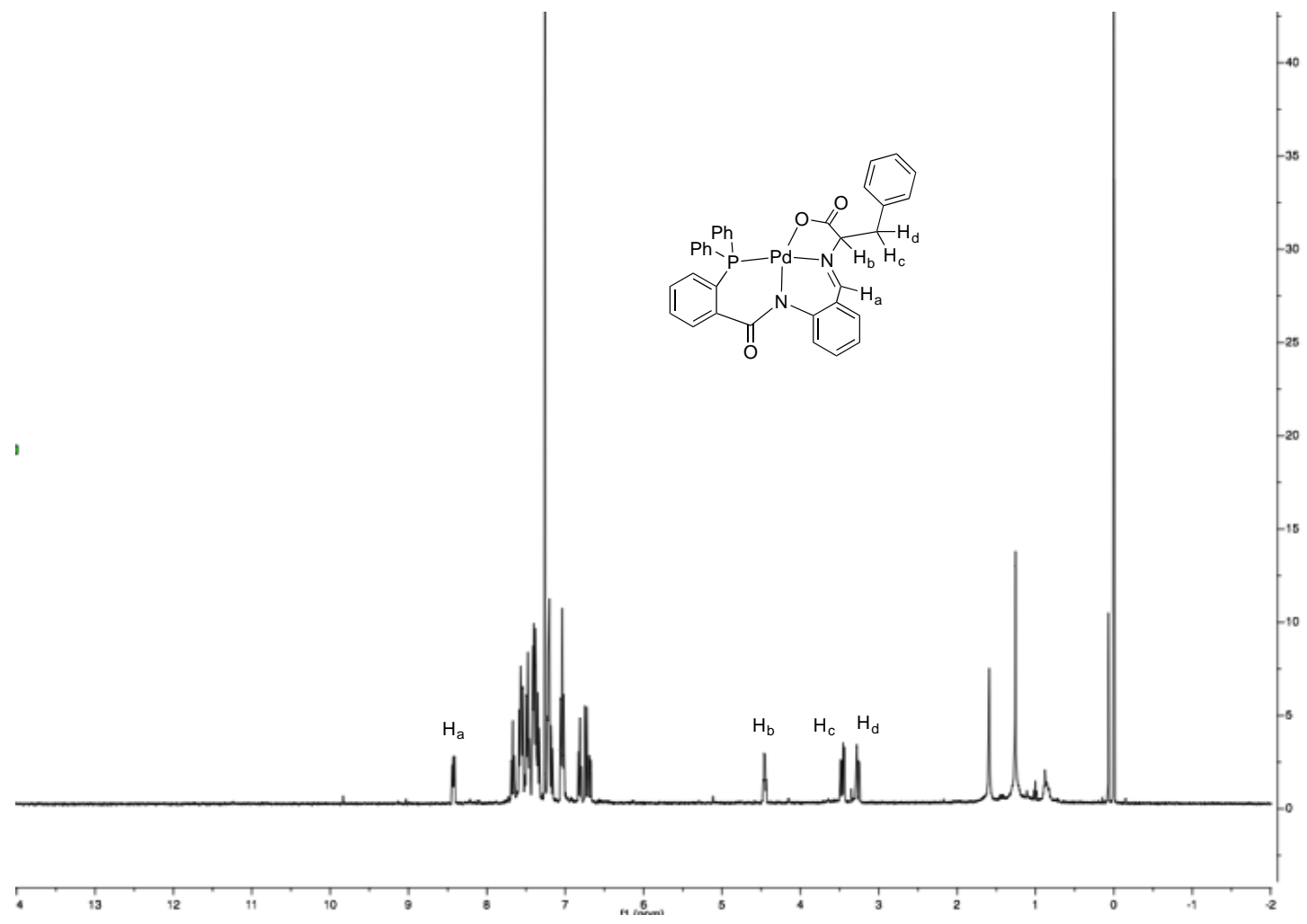

Sample concentrations were $0.01 \mathrm{M}$ in $\mathrm{CDCl}_{3}$. 


\subsection{CD spectroscopy}

The CD spectra of 1, $\mathrm{Pd}(\mathrm{OAc})_{2}$ and L-5 after 0, 2, $4,12,15,25,35$ and 45 minutes using sample concentrations of $2.50 \times 10^{-4} \mathrm{M}$ in chloroform were taken.

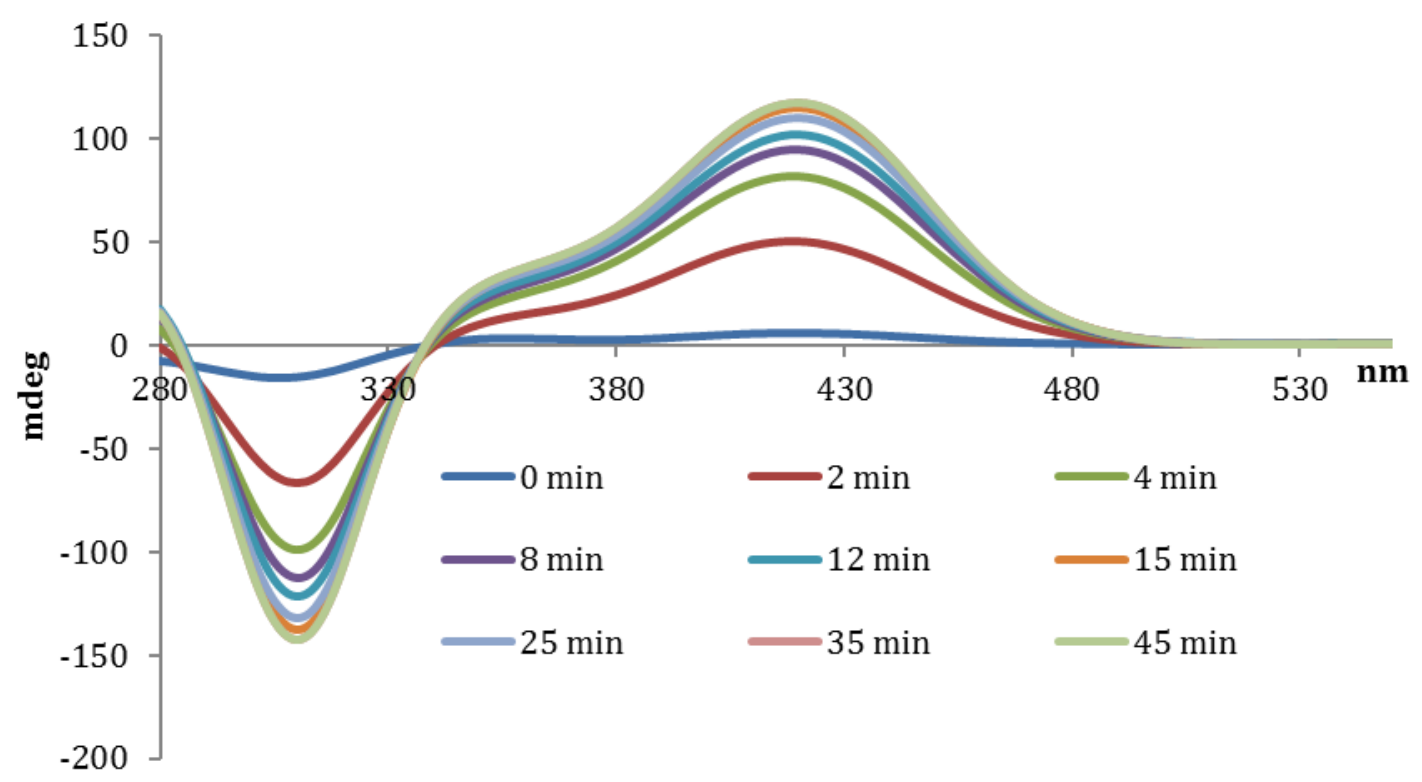

The amplitudes at $420 \mathrm{~nm}$ taken at different time were plotted versus time. After 12 minutes, the signal began to plateau indicating completion of the assembly.

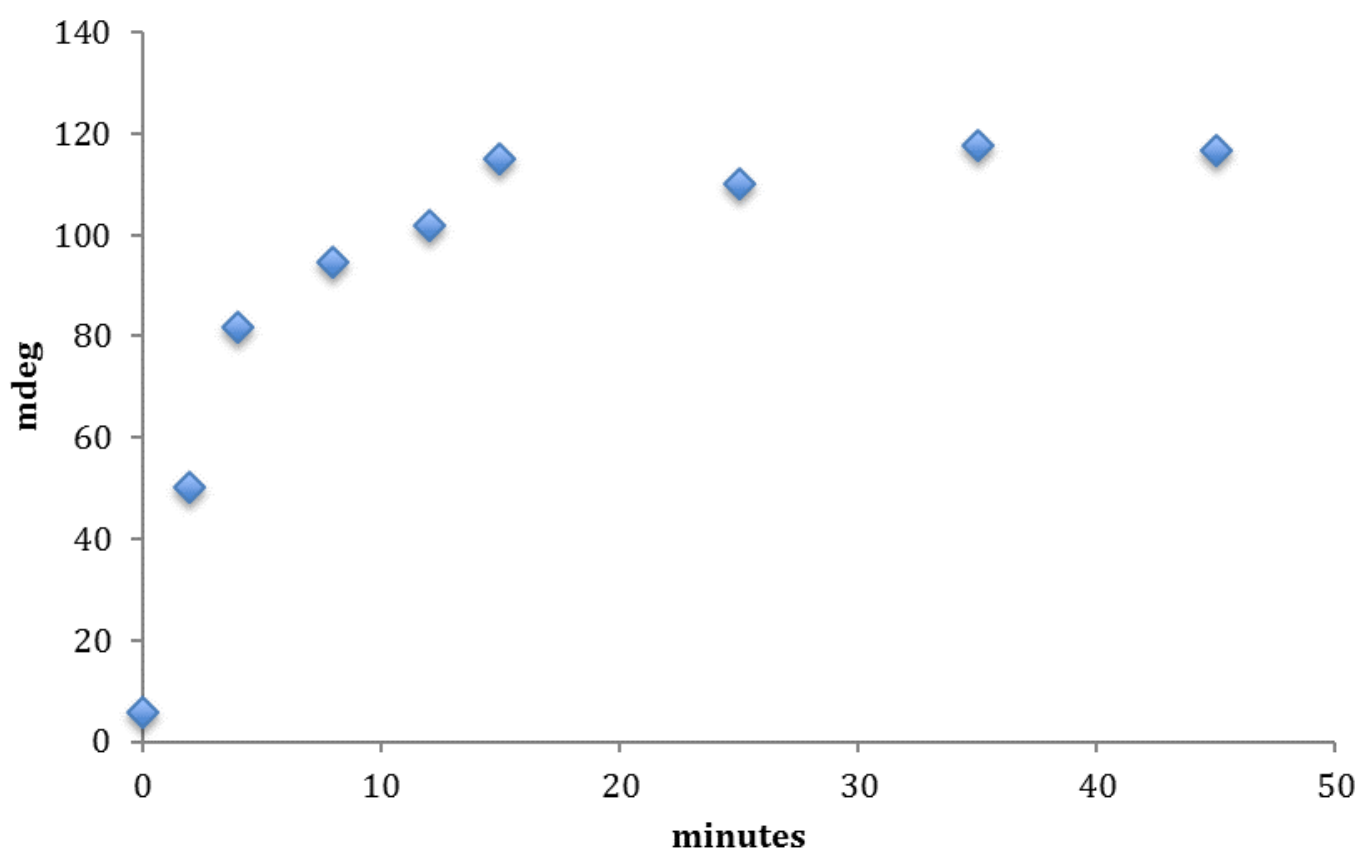




\section{Quantitative ee and concentration analysis of 5}

\subsection{Ee determination of amino acid 5}

Enantiomers of $\mathbf{5}$ with identical enantiopurity were purchased. A calibration curve was constructed using nonracemic samples of $\mathbf{5}$. A stock solution of $\mathbf{1}\left(0.01 \mathrm{M}\right.$ in $\left.\mathrm{CHCl}_{3}\right)$ was prepared and $0.5 \mathrm{~mL}$ portions were placed in $4 \mathrm{~mL}$ vials. Solutions of $5(0.50 \mathrm{M}$ in $\mathrm{MeOH})$ with equimolar amount of TBAOH and varying ee compositions $(+100.0,+80.0,+60.0$, $+40.0,+20.0,0.0,-20.0,-40.0,-60.0,-80.0,-100.0)$ and a $0.25 \mathrm{M}$ stock solution of $\mathrm{Pd}(\mathrm{OAc})_{2}$ in $\mathrm{CHCl}_{3}$ were prepared. To each vial containing $0.5 \mathrm{~mL}$ of the stock solution of 1 was added one equivalent $(0.01 \mathrm{~mL})$ of the the substrate and one equivalent $(0.02 \mathrm{~mL})$ of $\mathrm{Pd}(\mathrm{OAc})_{2}$ and the $\mathrm{CD}$ analysis was carried out as described above. The CD amplitudes measured at 310 and $420 \mathrm{~nm}$ were plotted against \%ee.

CD spectra of the imine complex obtained from 1, $\mathrm{Pd}(\mathrm{OAc})_{2}$ and varying ee compositions of 5

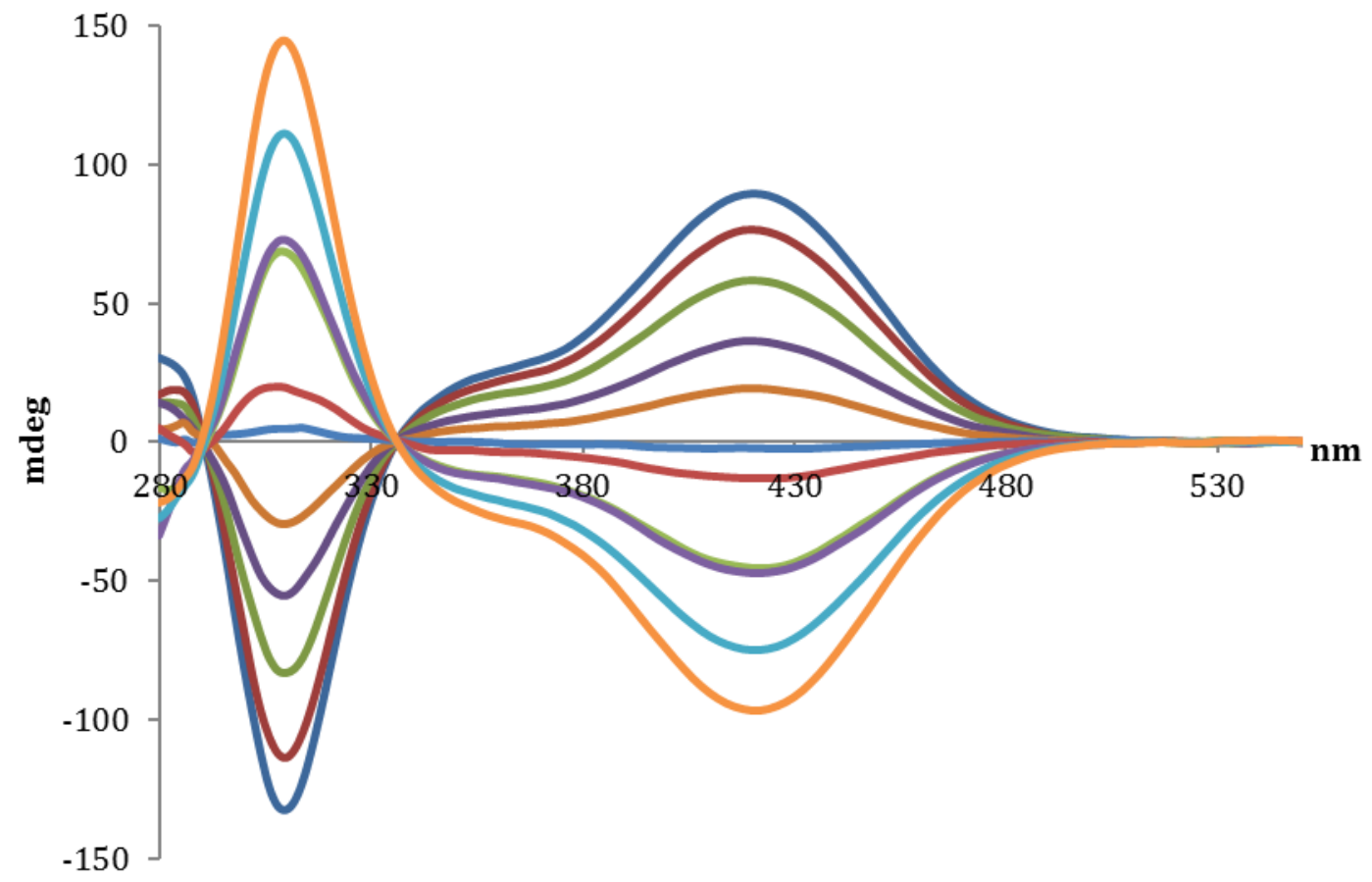


Linear relationship between the CD amplitudes at 310 and $420 \mathrm{~nm}$ and the enantiomeric excess of 5

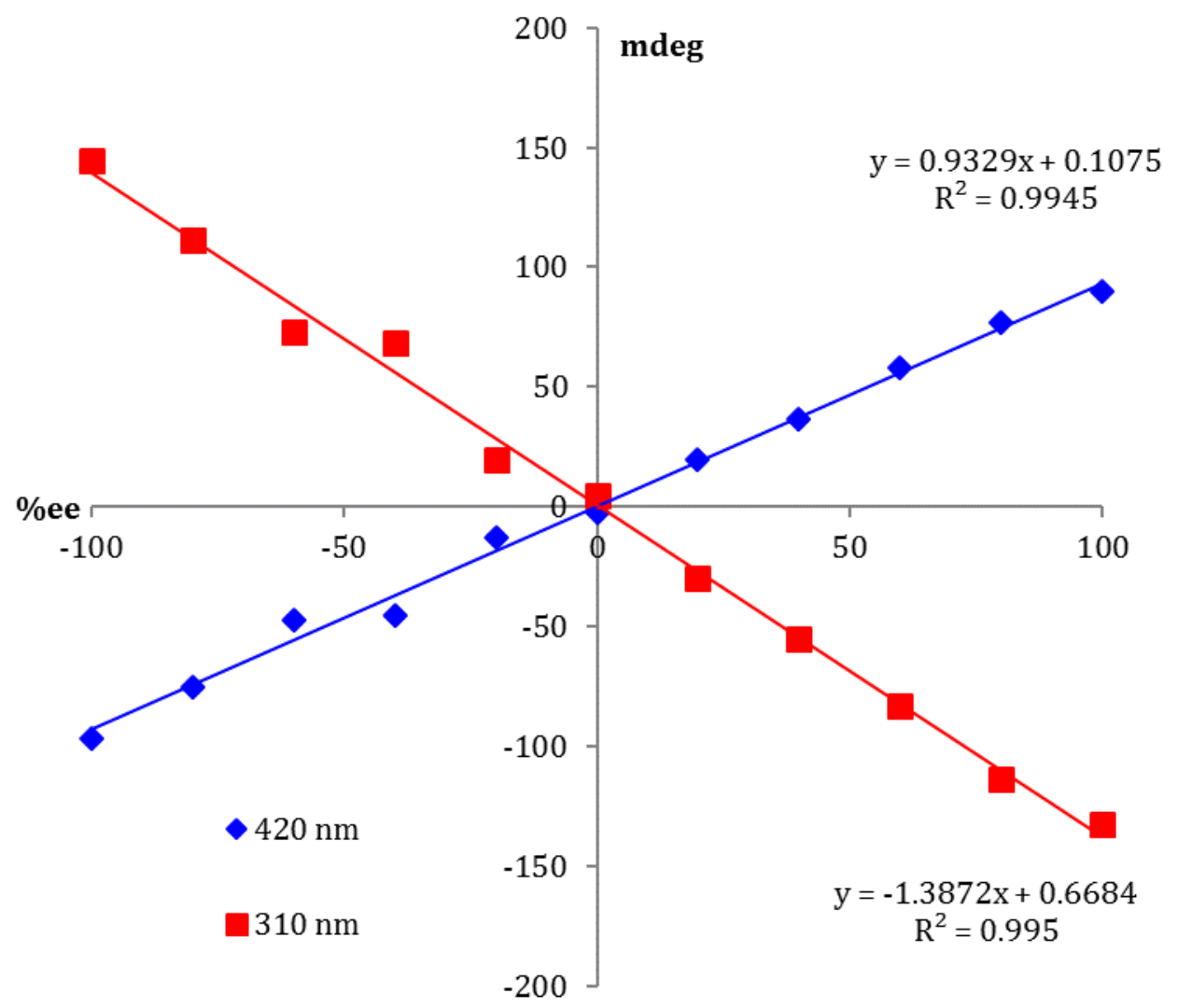

Five scalemic samples of $\mathbf{5}$ were prepared and then treated with the sensor as described above. Using the linear regression equation obtained from the calibration curves and the measured Cotton effect amplitude at both 310 and $420 \mathrm{~nm}$, the enantiomeric excess of these samples was determined.

Experimentally determined ee's of five scalemic samples of $\mathbf{5}$ using the CD maxima at 310 and $420 \mathrm{~nm}$.

\begin{tabular}{ccccccc}
\hline \multirow{2}{*}{ Sample Composition } & \multicolumn{2}{c}{$\begin{array}{c}\text { Chiroptical Sensing } \\
\text { Results }(310 \mathrm{~nm})\end{array}$} & $\begin{array}{c}\text { Chiroptical Sensing } \\
\text { Results }\end{array}$ (420 nm) & \\
\hline $\begin{array}{c}\text { Abs. } \\
\text { Config. }\end{array}$ & $\begin{array}{c}\text { Actual } \\
\text { \%ee }\end{array}$ & $\begin{array}{c}\text { Abs. } \\
\text { Config. }^{\text {a }}\end{array}$ & $\begin{array}{c}\text { Calculated } \\
\text { \%ee }\end{array}$ & $\begin{array}{c}\text { Abs. } \\
\text { Config. }^{\text {a }}\end{array}$ & $\begin{array}{c}\text { Calculated } \\
\text { \%ee }\end{array}$ & Average \%ee \\
\hline L & 76.0 & L & 77.6 & L & 77.7 & 77.6 \\
L & 12.0 & L & 6.6 & L & 7.6 & 7.1 \\
D & 26.0 & D & 31.5 & D & 30.3 & 30.9 \\
D & 68.0 & D & 71.3 & D & 71.2 & 71.3 \\
D & 89.0 & D & 88.3 & D & 88.1 & 88.2 \\
\hline
\end{tabular}

${ }^{\mathrm{a} B}$ Based on the sign of the $\mathrm{CD}$ response. ${ }^{\mathrm{b}}$ Based on the amplitude of the $\mathrm{CD}$ response 


\subsection{Determination of the concentration of 5}

The change in the UV signature upon addition of various amounts of $\mathbf{5}$ was analyzed. A stock solution of $1\left(0.01 \mathrm{M}\right.$ in $\left.\mathrm{CHCl}_{3}\right)$ was prepared and $0.5 \mathrm{~mL}$ portions were placed into $4 \mathrm{~mL}$ vials. Stock solutions of $5(0.50 \mathrm{M}$ in $\mathrm{MeOH})$ with equimolar amount of TBAOH and a 0.25 $\mathrm{M}$ solution of $\mathrm{Pd}(\mathrm{OAc})_{2}$ in $\mathrm{CHCl}_{3}$ were prepared. To the solutions of $\mathbf{1}$ were added one equivalent $(0.02 \mathrm{~mL})$ of $\mathrm{Pd}(\mathrm{OAc})_{2}$ and 5 in varying amounts $(0,20,40,60,80$ and 100 mol\%). UV spectra were collected with an average scanning time of $0.1 \mathrm{~s}$, a data interval of 1 $\mathrm{nm}$ and a scan rate of $600 \mathrm{~nm} / \mathrm{min}$. The UV absorbance at $390 \mathrm{~nm}$ decreased steadily upon addition of $\mathbf{5}$.

UV spectra of the sensor in the presence of varying amounts of 5

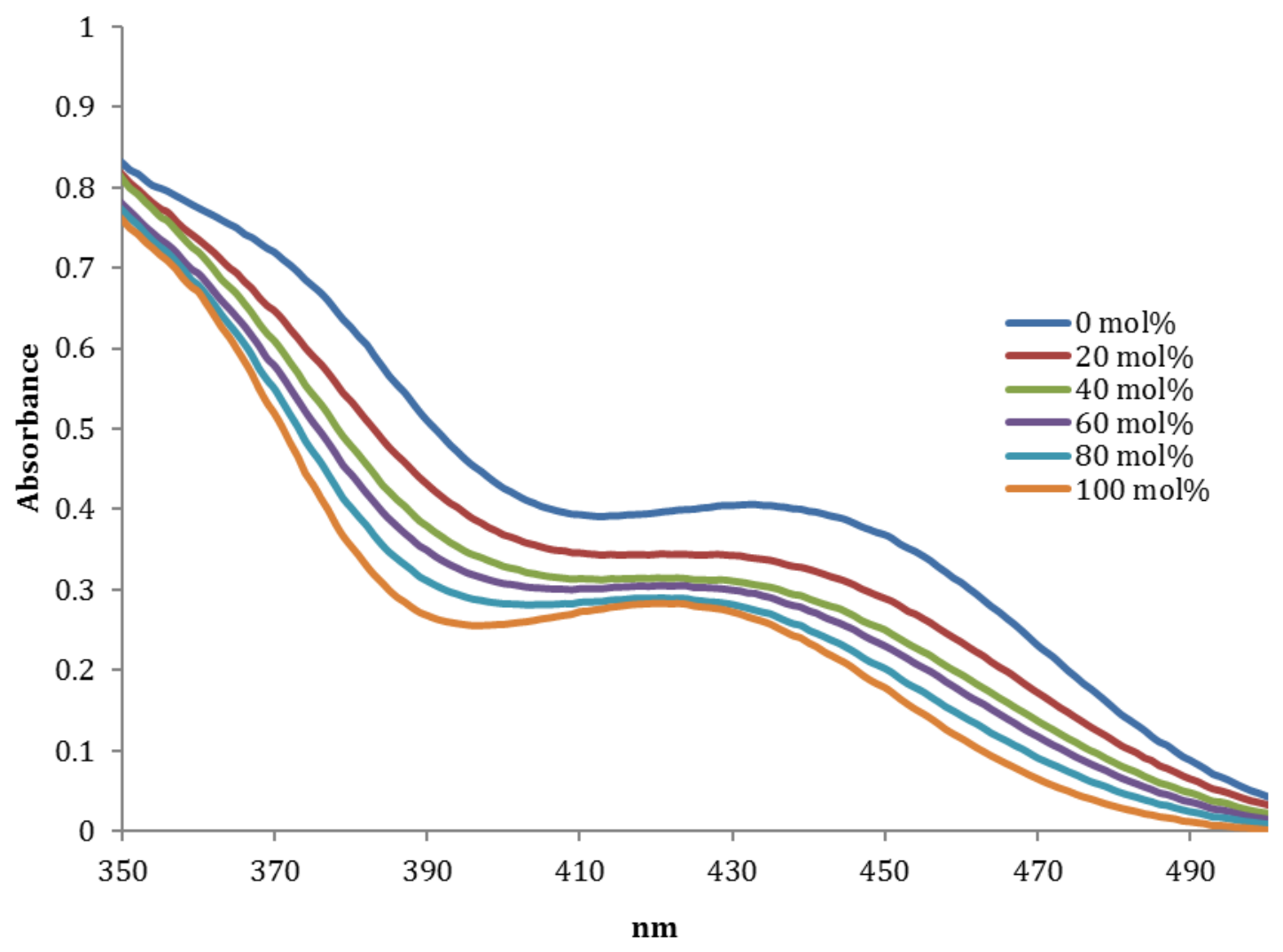


UV change at $390 \mathrm{~nm}$ upon complex formation of sensor with $\mathbf{5}$ ranging from 0 to $100 \mathrm{~mol} \%$

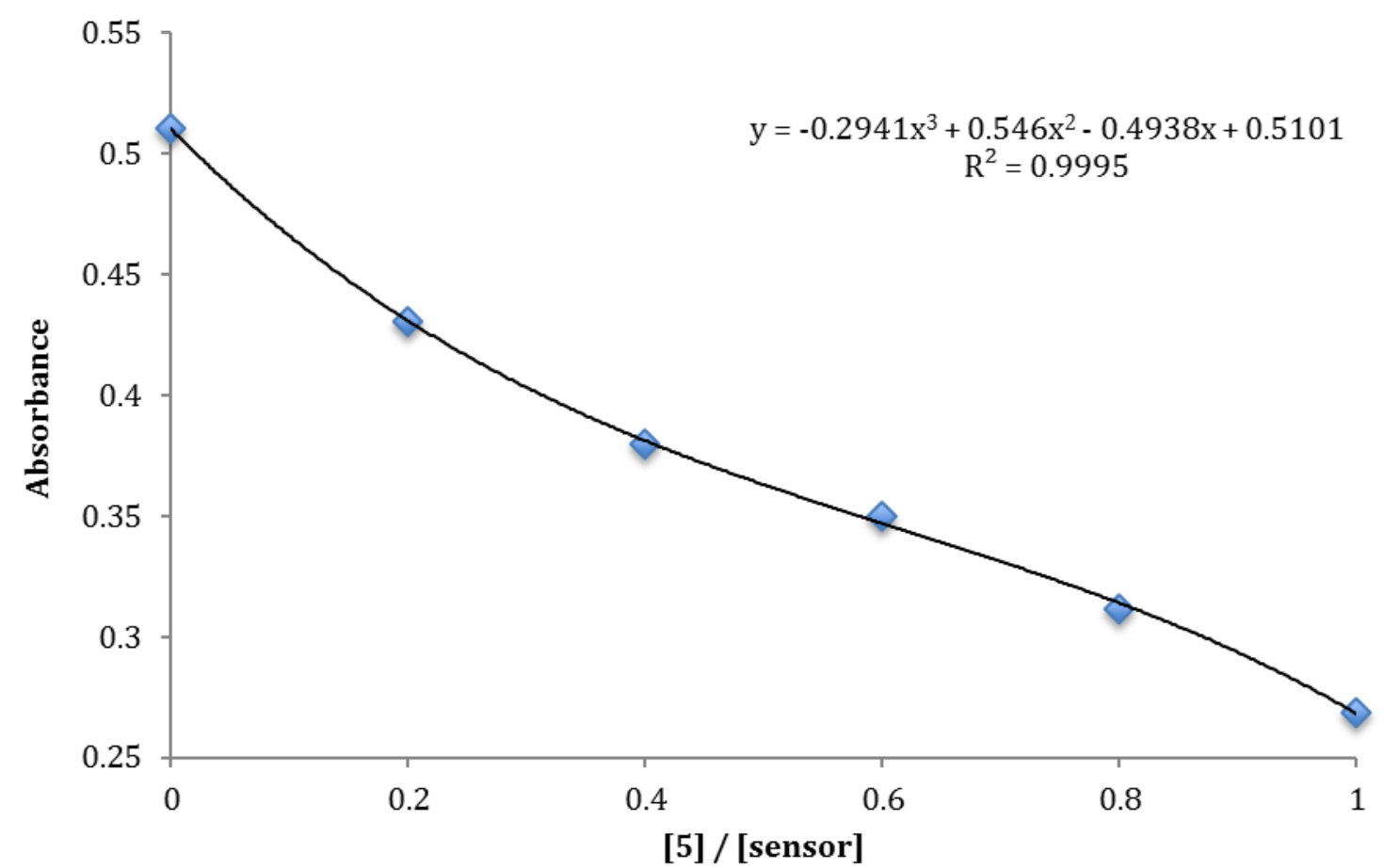

Four solutions of $\mathbf{5}$ at varying concentrations were prepared and analyzed as described above. Using the equation obtained from the calibration curve and the UV absorbance at $390 \mathrm{~nm}$, the concentrations of these samples were determined.

\begin{tabular}{cc}
\hline Concentration of $\mathbf{5}(\mathrm{mM})$ & Sensing result $(\mathrm{mM})$ \\
\hline 1.5 & 1.8 \\
3.5 & 3.5 \\
5.5 & 6.0 \\
8.5 & 8.3 \\
\hline
\end{tabular}




\section{Quantitative ee and concentration analysis of $\mathbf{2 3}$}

\subsection{Ee determination of amine 23}

A calibration curve was constructed using nonracemic samples of 23. A stock solution of $\mathbf{1}$ $\left(0.01 \mathrm{M}\right.$ in $\left.\mathrm{CHCl}_{3}\right)$ was prepared and $0.5 \mathrm{~mL}$ portions were placed in $4 \mathrm{~mL}$ vials. Solutions of $23(0.50 \mathrm{M}$ in $\mathrm{MeOH})$ with equimolar amount of $\mathrm{TBAOH}$ and varying ee compositions $(+100.0,+80.0,+60.0,+40.0,0.0,-40.0,-60.0,-80.0,-100.0)$ and a $0.25 \mathrm{M}$ stock solution of $\mathrm{Pd}(\mathrm{OAc})_{2}$ in $\mathrm{CHCl}_{3}$ were prepared. To each vial containing $0.5 \mathrm{~mL}$ of the stock solution of 1 was added one equivalent $(0.01 \mathrm{~mL})$ of the substrate and one equivalent $(0.02 \mathrm{~mL})$ of $\mathrm{Pd}(\mathrm{OAc})_{2}$ and the $\mathrm{CD}$ analysis was carried out as described above. The $\mathrm{CD}$ amplitudes measured at 310 and $415 \mathrm{~nm}$ were plotted against \%ee.

CD spectra of the imine complex obtained from $\mathbf{1}, \mathrm{Pd}(\mathrm{OAc})_{2}$, and varying compositions of $\mathbf{2 3}$

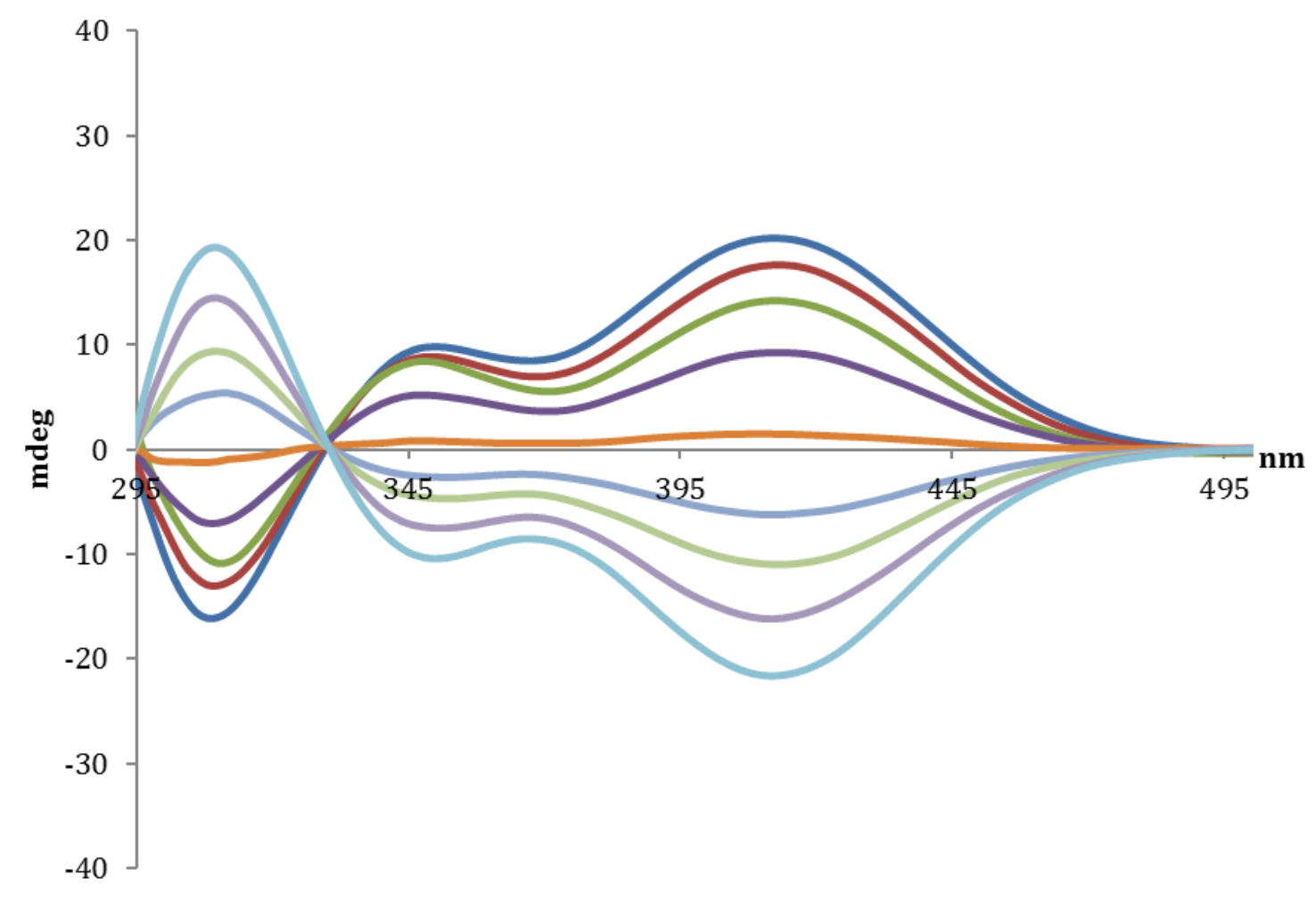


Linear relationship between the CD amplitudes at 310 and $415 \mathrm{~nm}$ and the enantiomeric excess of $\mathbf{2 3}$

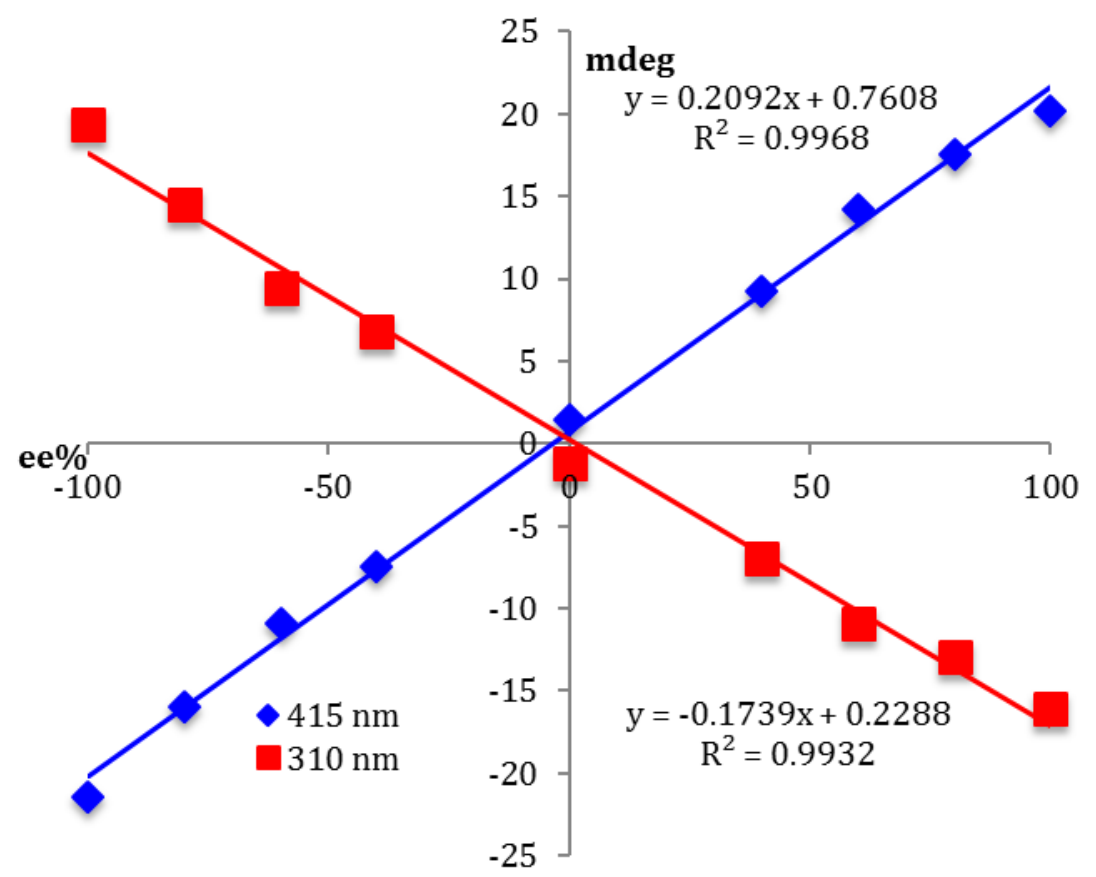

Three scalemic samples of $\mathbf{2 3}$ were prepared and then treated with the sensor as described above. Using the linear regression equation obtained from the calibration curves and the measured Cotton effect amplitude at both 310 and $415 \mathrm{~nm}$, the enantiomeric excess of these samples was determined.

Experimentally determined ee's of three scalemic samples of $\mathbf{2 3}$ using the CD maxima at 310 and $415 \mathrm{~nm}$

\begin{tabular}{|c|c|c|c|c|c|c|}
\hline \multicolumn{2}{|c|}{ Sample Composition } & \multicolumn{2}{|c|}{$\begin{array}{l}\text { Chiroptical Sensing } \\
\text { Results }(310 \mathrm{~nm})\end{array}$} & \multicolumn{2}{|c|}{$\begin{array}{l}\text { Chiroptical Sensing } \\
\text { Results (415 nm) }\end{array}$} & \multirow[b]{2}{*}{ Average \%ee } \\
\hline $\begin{array}{l}\text { Abs. } \\
\text { Config. }\end{array}$ & $\begin{array}{l}\text { Actual } \\
\% \text { ee }\end{array}$ & $\begin{array}{c}\text { Abs. } \\
\text { Config. }\end{array}$ & $\begin{array}{c}\text { Calculated } \\
\% \text { ee }^{\mathrm{b}}\end{array}$ & $\begin{array}{c}\text { Abs. } \\
\text { Config. }\end{array}$ & $\begin{array}{c}\text { Calculated } \\
\% e^{b}\end{array}$ & \\
\hline$R$ & 76.0 & $R$ & 68.9 & $R$ & 75.3 & 72.1 \\
\hline$R$ & 12.0 & $R$ & 9.2 & $R$ & 11.1 & 10.2 \\
\hline$S$ & 68.0 & $S$ & 68.0 & $S$ & 63.2 & 65.6 \\
\hline
\end{tabular}

${ }^{\mathrm{a}}$ Based on the sign of the CD response. ${ }^{\mathrm{b}} \mathrm{Based}$ on the amplitude of the CD response. 


\subsection{Determination of the concentration of 23}

The change in the UV signature upon addition of various amounts of 23 was analyzed. A stock solution of $1\left(0.01 \mathrm{M}\right.$ in $\left.\mathrm{CHCl}_{3}\right)$ was prepared and $0.5 \mathrm{~mL}$ portions were placed into 4 $\mathrm{mL}$ vials. Stock solutions of $23(0.50 \mathrm{M}$ in $\mathrm{MeOH})$ with equimolar amount of TBAOH and a $0.25 \mathrm{M}$ solution of $\mathrm{Pd}(\mathrm{OAc})_{2}$ in $\mathrm{CHCl}_{3}$ were prepared. To the solutions of 1 were added one equivalent $(0.02 \mathrm{~mL})$ of $\mathrm{Pd}(\mathrm{OAc})_{2}$ and 23 in varying amounts $(0,20,40,60$ and $100 \mathrm{~mol} \%)$. UV spectra were collected with an average scanning time of $0.1 \mathrm{~s}$, a data interval of $1 \mathrm{~nm}$ and a scan rate of $600 \mathrm{~nm} / \mathrm{min}$. The UV absorbance at $450 \mathrm{~nm}$ decreased steadily upon addition of 23.

UV spectra of the sensor in the presence of varying amount of 23

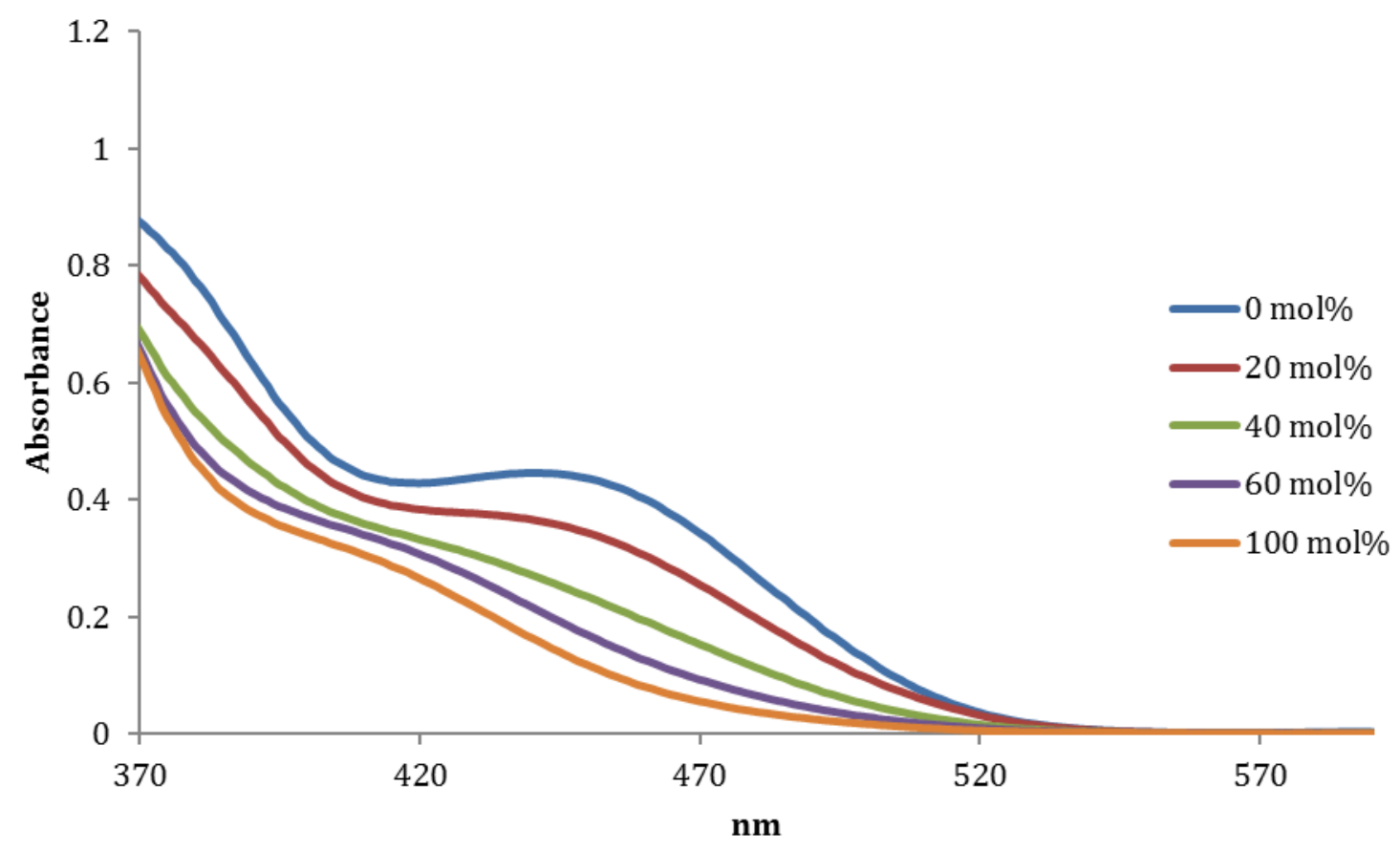


UV change at $450 \mathrm{~nm}$ upon complex formation of sensor with 23 ranging from 0 to 100 $\mathrm{mol} \%$

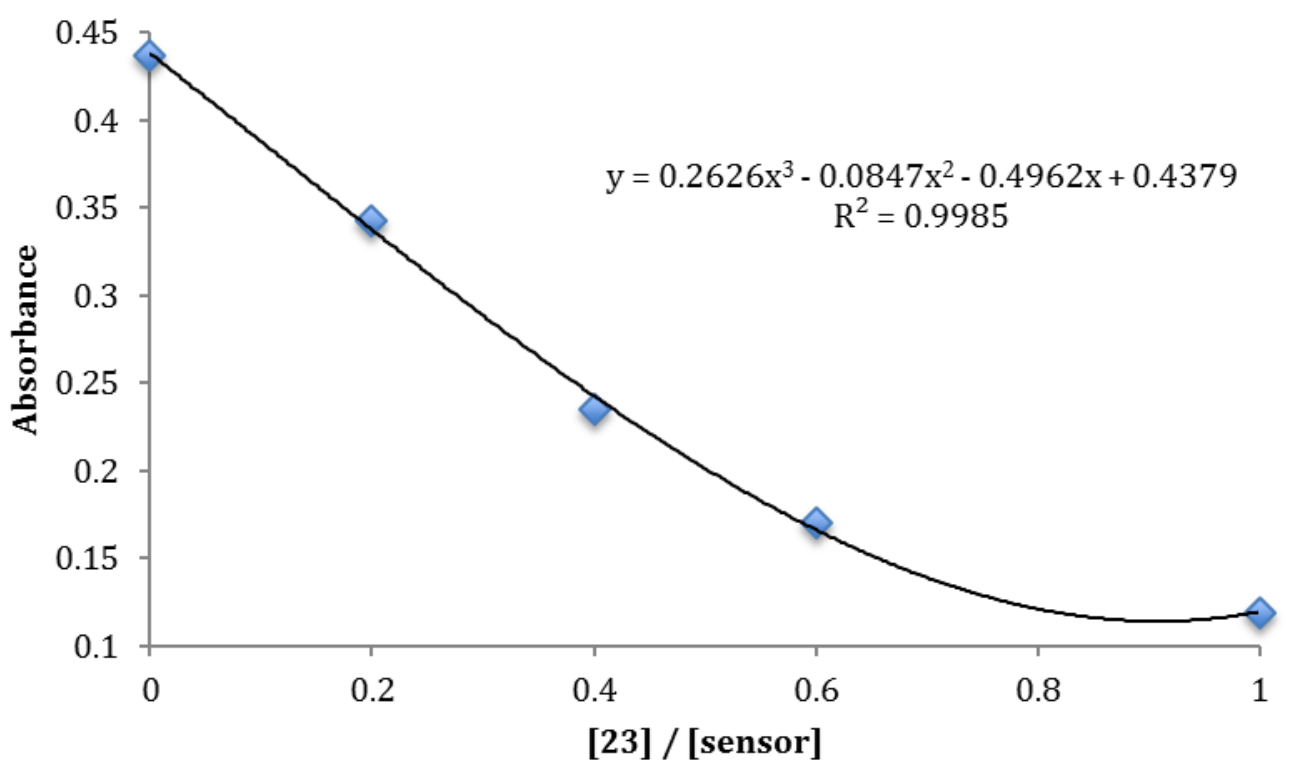

Four solutions of $\mathbf{2 3}$ at varying concentrations were prepared and analyzed as described above. Using the equation obtained from the calibration curve and the UV absorbance at 450 $\mathrm{nm}$, the concentrations of these samples were determined.

\begin{tabular}{cc}
\hline Concentration of $\mathbf{2 3}(\mathrm{mM})$ & Sensing result $(\mathrm{mM})$ \\
\hline 3.5 & 2.7 \\
5.5 & 5.0 \\
7.5 & 7.5 \\
9.5 & 8.9 \\
\hline
\end{tabular}




\section{Ee and concentration analysis of amine 23 obtained by enantioselective hydrogenation of 1-phenylethan-1-iminium chloride 26}
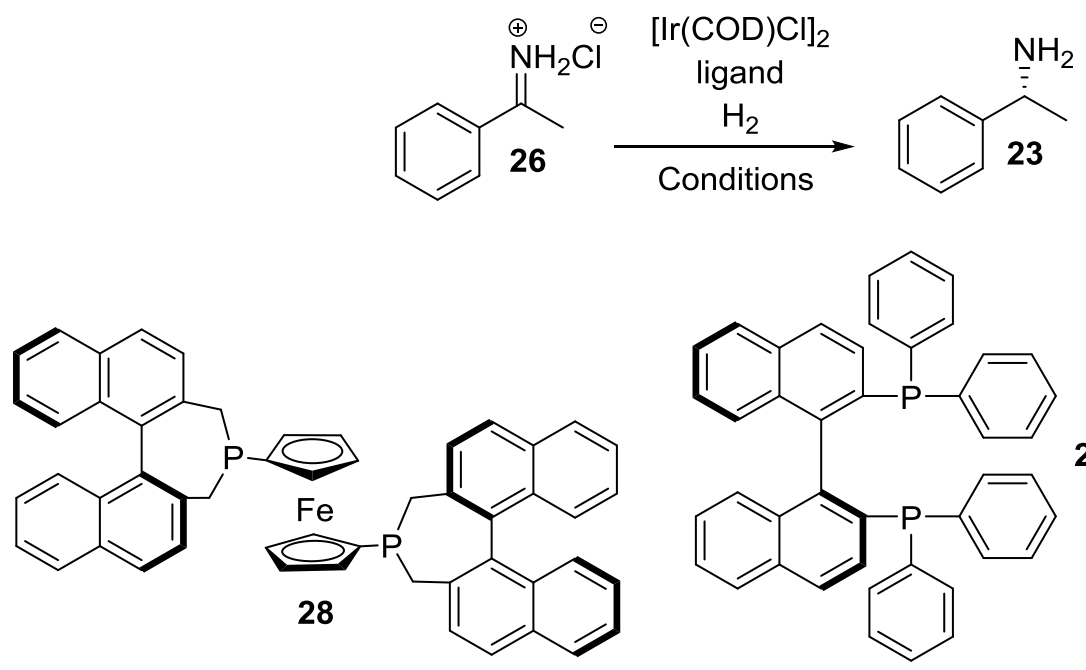

29<smiles>O=C(Nc1cc(C(F)(F)F)cc(C(F)(F)F)c1)N[C@H]1CCCC[C@H]1Pc1ccccc1</smiles>

The efficacy of the sensor assay for the determination of both the concentration and ee was tested using the enantioselective hydrogenation of $\mathbf{2 6}$ as an example. ${ }^{2}$ The enantioselective reduction of 26 (38.9 mg, $0.25 \mathrm{mmol}$ ) was performed using 5 or $10 \mathrm{~mol} \%$ of an iridium complex that was prepared by dissolving $[\operatorname{Ir}(\mathrm{COD}) \mathrm{Cl}]_{2}$ and a phosphine ligand (1:1 ratio or 1:2 with 29) in $2 \mathrm{~mL}$ of DCM. The solution was stirred for 1 hour. To this solution, 26 dissolved in $4 \mathrm{~mL}$ of $\mathrm{MeOH}$ was added and the mixture was placed in a hydrogenation vessel. The $\mathrm{H}_{2}$ pressure was set at 150 psi and the mixture was stirred at room temperature for 24 hours unless noted otherwise. Upon completion, the crude mixture was concentrated and was dissolved in $3 \mathrm{~mL}$ of $\mathrm{MeOH}$ and $\mathrm{CHCl}_{3}(2: 1)$.

For sensing analysis, compound $1(2.05 \mathrm{mg}, 0.005 \mathrm{mmol})$ was dissolved in $0.5 \mathrm{~mL}$ of $\mathrm{CHCl}_{3}$. To this solution, $\mathrm{Pd}(\mathrm{OAc})_{2}(0.02 \mathrm{~mL}, 0.005 \mathrm{mmol})$, TBAOH $(0.01 \mathrm{~mL}, 0.010 \mathrm{mmol})$ and a portion $(0.06 \mathrm{~mL})$ of the crude reaction mixture that would have had an equimolar amount of 1 if the reaction yield was $100 \%$, was added. A UV-Vis spectrum was obtained via the method described in Section 5.2. Then, a CD spectrum was obtained via the method described in Section 5.1. The measured CD amplitude at $415 \mathrm{~nm}$ was normalized for the concentration calculated by the UV-Vis analysis as shown in equation 1 . This value was then applied in the linear regression equation obtained in section 5.1 to determine the enantiomeric excess of 23. 


\section{Equation 1}

\section{Equation 2}

$e e=\frac{\frac{m d e g}{\chi}-0.7608}{0.2092}$

$$
\begin{gathered}
X=0.2626 x^{3}-0.0847 x^{2}-0.49962 x+ \\
(0.4379-\text { UV Abs }[450 \mathrm{~nm}])
\end{gathered}
$$

Comparison of the ee and yield of $\mathbf{2 3}$ obtained by enantioselective hydrogenation of $\mathbf{2 6}$.

\begin{tabular}{ccccccc}
\hline & & & \multicolumn{2}{c}{ Conventional } & \multicolumn{2}{c}{ Sensing } \\
& & & \multicolumn{2}{c}{ Analysis } & \multicolumn{2}{c}{ Results } \\
\hline \multirow{2}{*}{ Entry } & Ligand & Time & $\begin{array}{c}\text { Isolated } \\
\text { Yield (\%) }\end{array}$ & $\begin{array}{c}\text { \%ee by } \\
\text { HPLC }(R)\end{array}$ & $\begin{array}{c}\text { Calculated } \\
\text { Yield (\%) }\end{array}$ & $\begin{array}{c}\text { \%ee at } \\
415 \mathrm{~nm}(R)\end{array}$ \\
\hline $1^{\mathrm{a}}$ & $\mathbf{2 8}$ & $24 \mathrm{~h}$ & 70.6 & 44.4 & 65.4 & 38.6 \\
$2^{\mathrm{a}}$ & $\mathbf{2 8}$ & $48 \mathrm{~h}$ & 52.7 & 33.8 & 59.4 & 37.8 \\
$3^{\mathrm{b}}$ & $\mathbf{2 8}$ & $24 \mathrm{~h}$ & 70.2 & 64.0 & 61.1 & 62.6 \\
$4^{\mathrm{b}}$ & $\mathbf{2 9}$ & $24 \mathrm{~h}$ & 72.4 & 10.2 & 78.2 & 12.5 \\
$5^{\mathrm{c}}$ & $\mathbf{3 0}$ & $24 \mathrm{~h}$ & 69.3 & 0.7 & 68.3 & 0.4
\end{tabular}

Reaction conditions: ${ }^{\mathrm{a}}[\operatorname{Ir}(\mathrm{COD}) \mathrm{Cl}]_{2} /$ phosphine/substrate $=2.5 / 5 / 100,2: 1 \mathrm{MeOH} / \mathrm{DCM}, 25^{\circ} \mathrm{C}$, $150 \mathrm{psi}$ of $\mathrm{H}_{2} .{ }^{\mathrm{b}}[\mathrm{Ir}(\mathrm{COD}) \mathrm{Cl}]_{2} /$ phosphine/substrate $=5 / 10 / 100,2: 1 \mathrm{MeOH} / \mathrm{DCM}, 25^{\circ} \mathrm{C}, 150$ psi of $\mathrm{H}_{2} \cdot{ }^{c}[\mathrm{Ir}(\mathrm{COD}) \mathrm{Cl}]_{2} /$ phosphine/substrate $=5 / 20 / 100,2: 1 \mathrm{MeOH} / \mathrm{DCM}, 25^{\circ} \mathrm{C}, 150 \mathrm{psi}$ of $\mathrm{H}_{2}$.

For traditional analysis, the reaction products were purified via flash column chromatography (DCM:MeOH:Et ${ }_{3} \mathrm{~N}, 98: 2: 2$ ) for gravimetric analysis of the yield. The purified amine was then treated with $\mathrm{Ac}_{2} \mathrm{O}(51.1 \mathrm{mg}, 0.50 \mathrm{mmol})$ and DIPEA $(64.6 \mathrm{mg}, 0.50 \mathrm{mmol})$. The mixture was stirred for 1 hour. The crude reaction mixture was washed with water and the organic layer was concentrated and used without further purification for HPLC analysis.

Overall, the determination of the ee and concentration of 23 by chiroptical sensing required less time and solvent than the traditional column chromatography purification for gravimetric analysis and HPLC analysis. The chiroptical measurements required a total of $4 \mathrm{~mL}$ of solvent and the total time for stirring and each spectroscopic measurement was less than 35 minutes. By contrast, the purification of the reaction mixture by flash chromatography required $250 \mathrm{~mL}$ of solvent and took about 15 minutes and an additional 5 minutes to remove 
all the organic solvents. Acetylation of the amine was completed within one hour. The HPLC analysis required $13 \mathrm{~mL}$ of mobile phase (95:5 hexanes:EtOH) and typically took $25-30$ minutes. Altogether, $263 \mathrm{~mL}$ of solvent were consumed and the analysis time was 105 to 120 minutes per sample.

HPLC separation of a prepared mixture of $\mathrm{N}$-acetyl phenylethylamine, 27, (50\% ee) on Phenomenex Lux Amylose-1 using hexanes:EtOH (95:5 v/v) as mobile phase with a flow rate of $0.5 \mathrm{~mL} / \mathrm{min}$. The $(R)$-enantiomer eluted first.

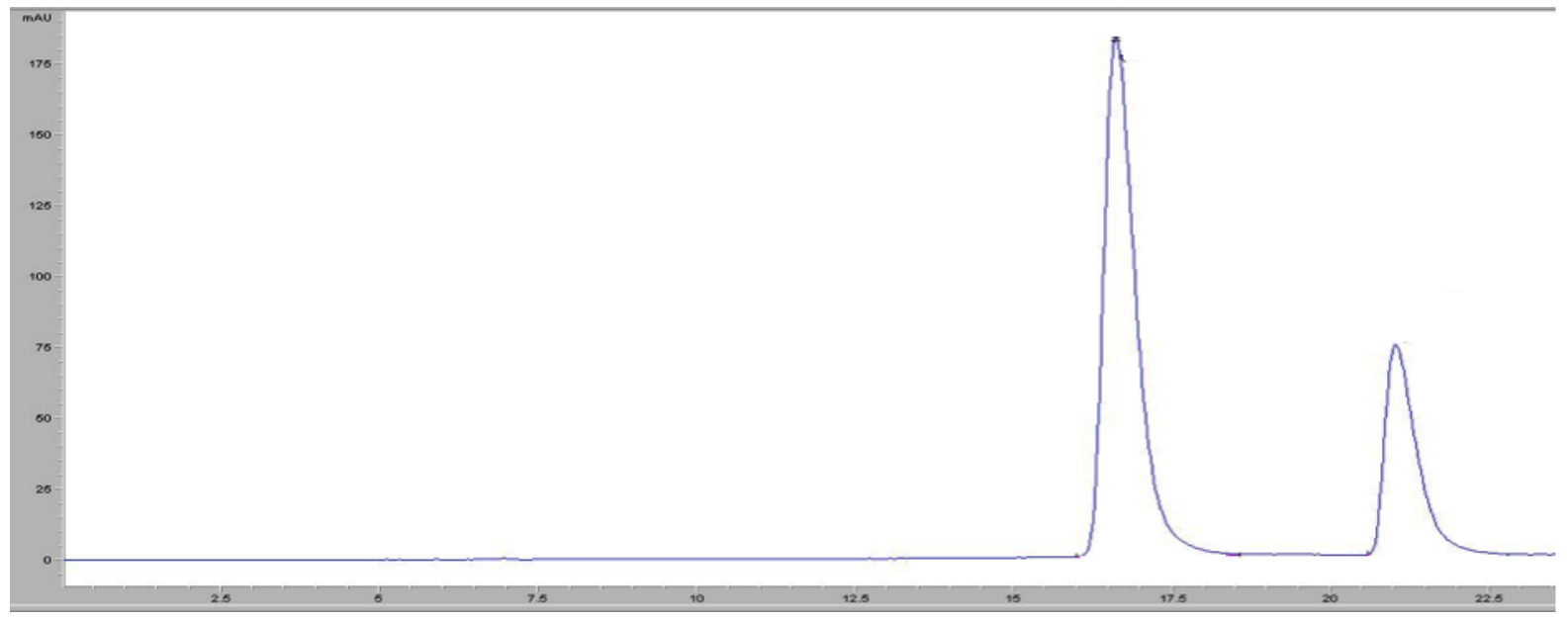

HPLC separation of the product obtained from entry 1 on Phenomenex Lux Amylose- 1 using hexanes:EtOH (95:5 v/v) as mobile phase with a flow rate of $0.5 \mathrm{~mL} / \mathrm{min}$.

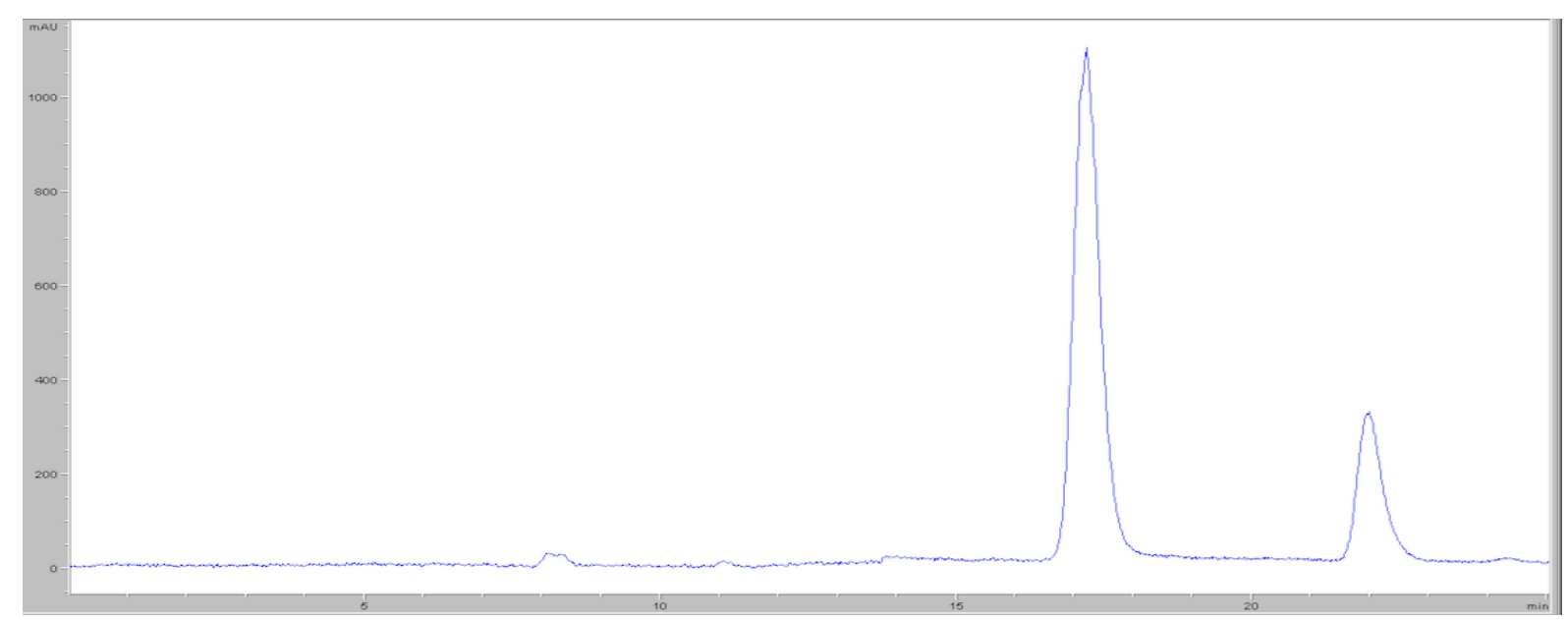

HPLC separation of the product obtained from entry 2 on Phenomenex Lux Amylose-1 using hexanes:EtOH (95:5 v/v) as mobile phase with a flow rate of $0.5 \mathrm{~mL} / \mathrm{min}$. 


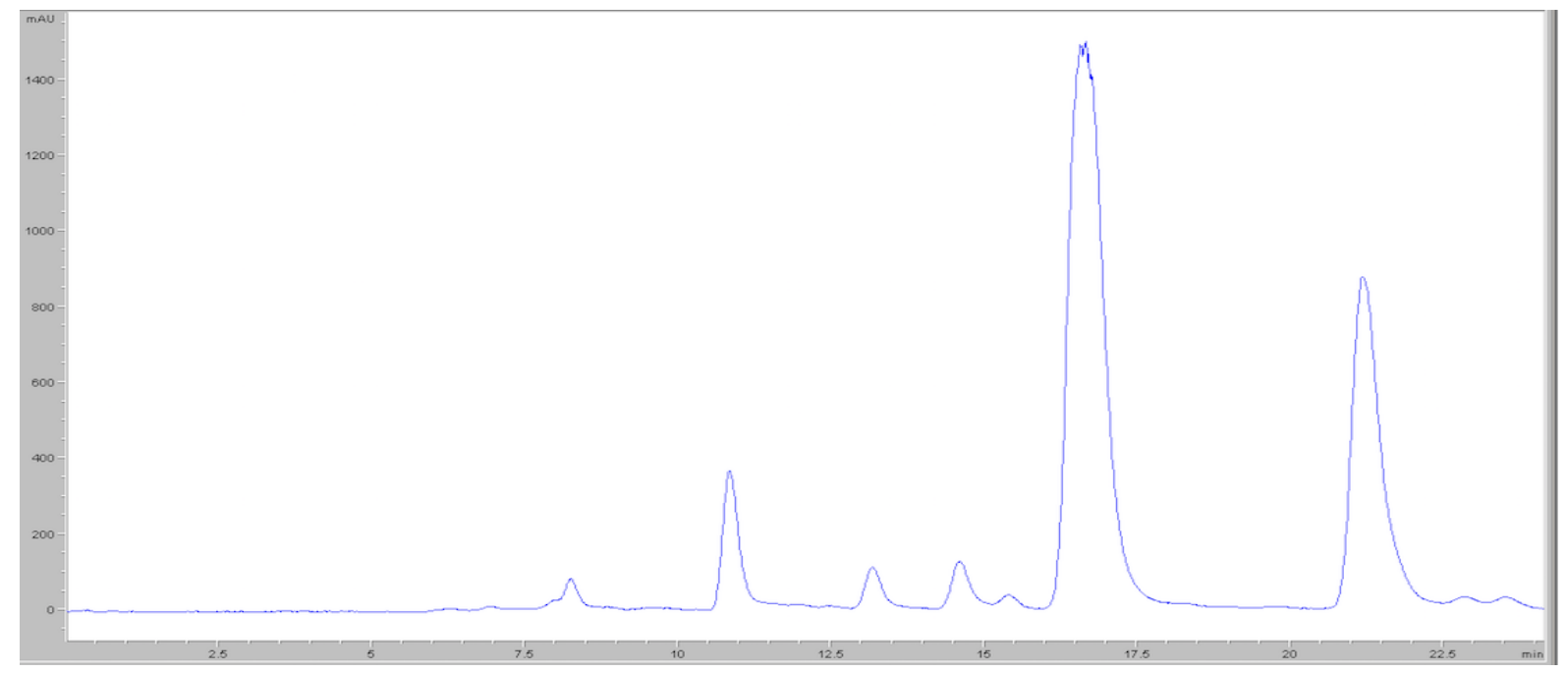

HPLC separation of the product obtained from entry 3 on Phenomenex Lux Amylose-1 column hexanes:EtOH $(95: 5 \mathrm{v} / \mathrm{v})$ as mobile phase with a flow rate of $0.5 \mathrm{~mL} / \mathrm{min}$.

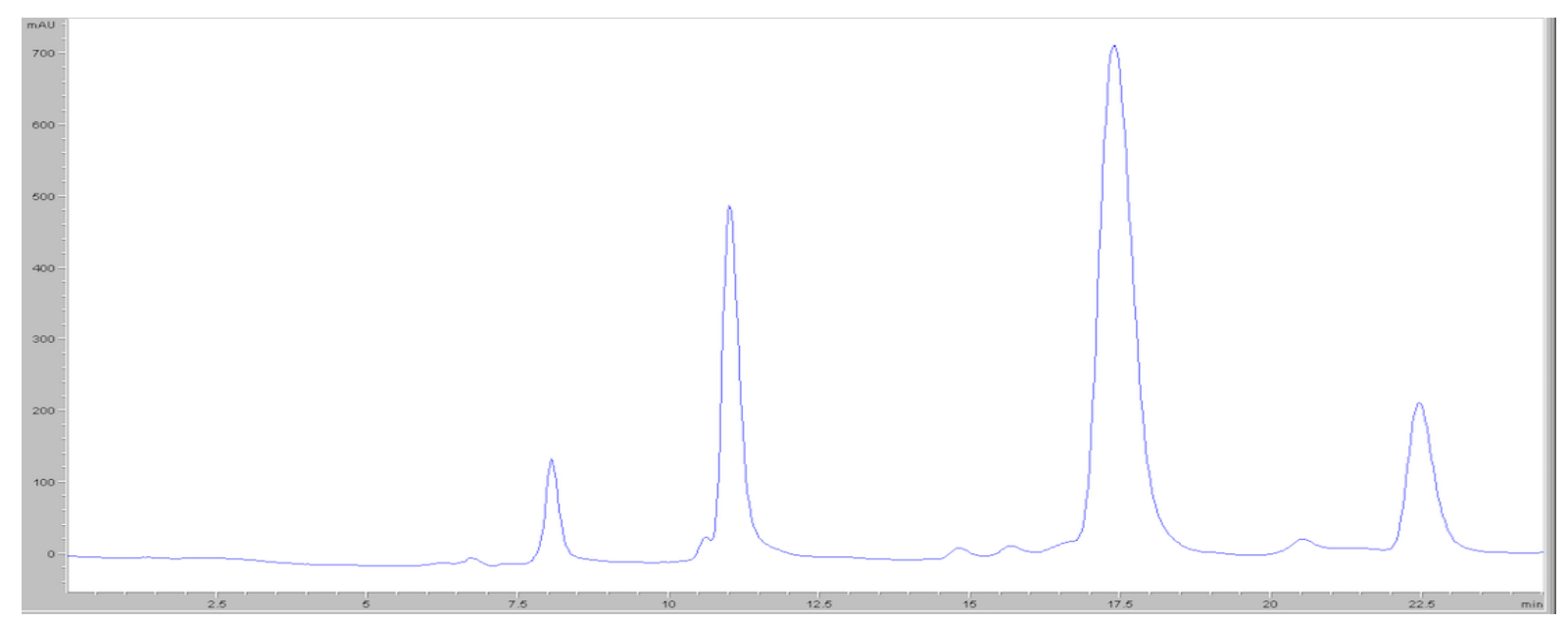

HPLC separation of the product obtained from entry 4 on Phenomenex Lux Amylose-1 using hexanes:EtOH $(95: 5 \mathrm{v} / \mathrm{v})$ as mobile phase with a flow rate of $0.5 \mathrm{~mL} / \mathrm{min}$. 


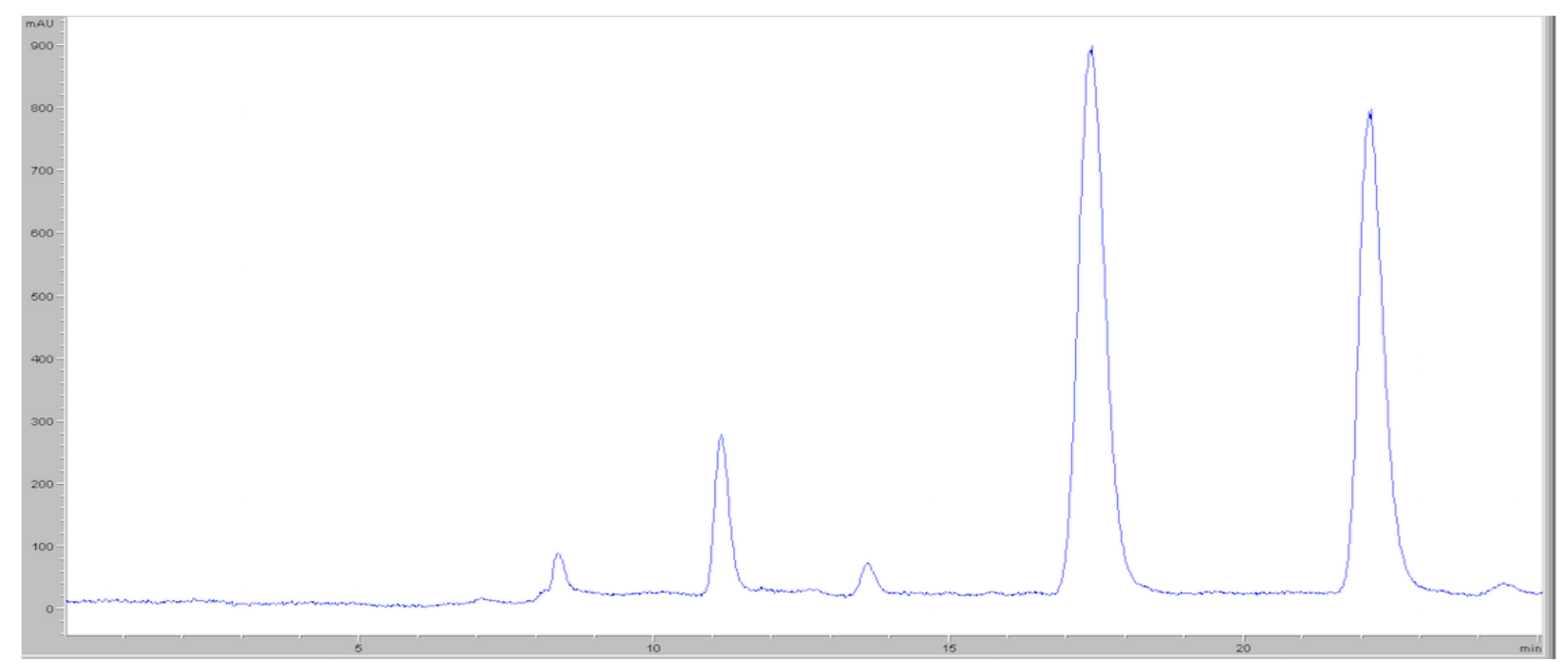

HPLC separation of the product obtained from entry 5 on Phenomenex Lux Amylose-1 using hexanes:EtOH $(96: 4 \mathrm{v} / \mathrm{v})$ as mobile phase with a flow rate of $0.5 \mathrm{~mL} / \mathrm{min}$.

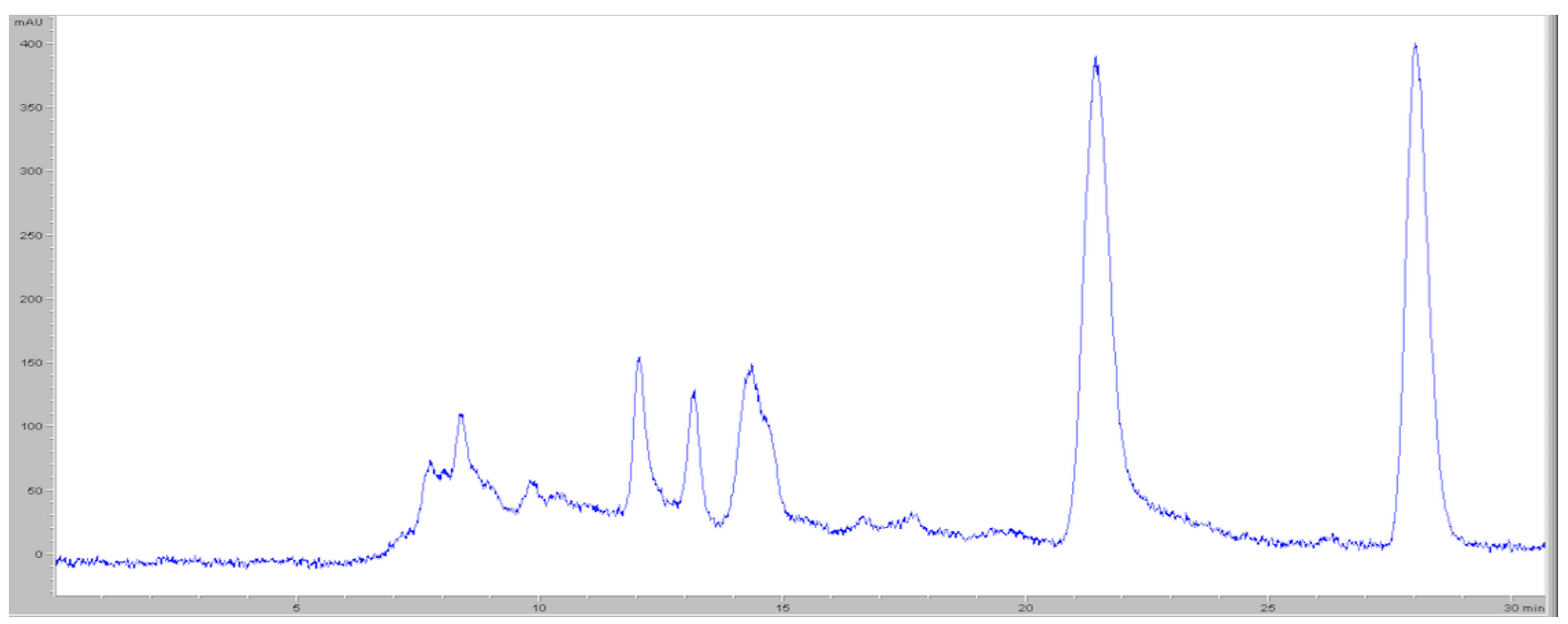




\section{Crystallographic data}

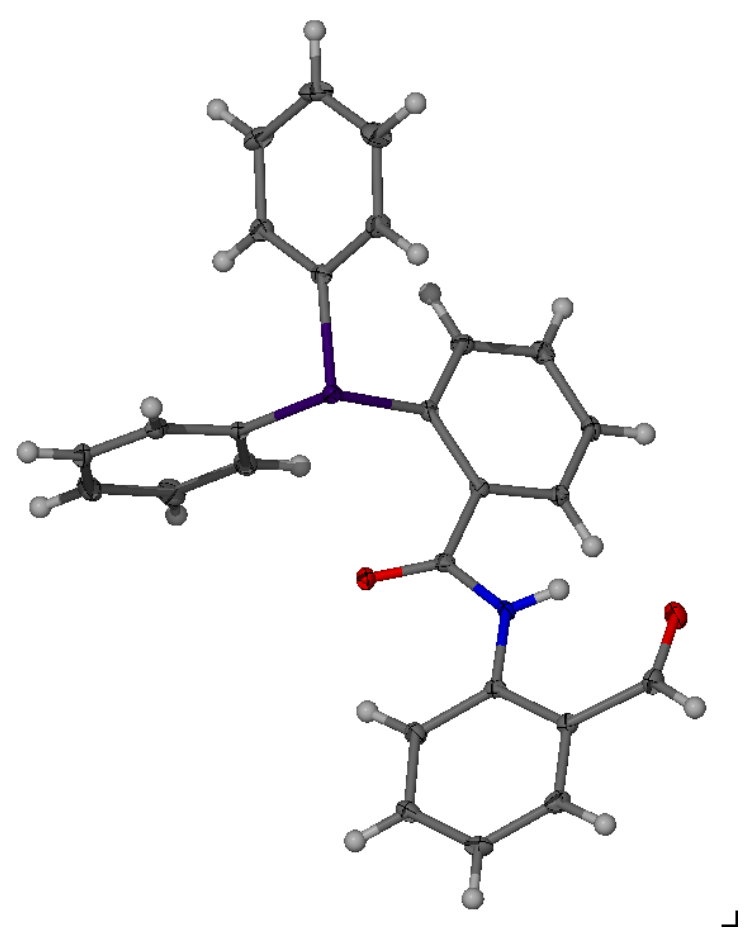

\section{2-(Diphenylphosphanyl)- $N$-(2-formylphenyl)benzamide}

A single crystal was obtained by slow evaporation of a solution of the aldehyde in $\mathrm{CDCl}_{3}$. Single crystal X-ray analysis was performed at $100 \mathrm{~K}$ using a Siemens platform diffractometer with graphite monochromated Mo-K $\alpha$ radiation $(\lambda=0.71073 \AA)$. Data were integrated and corrected using the Apex 2 program. The structures were solved by direct methods and refined with full-matrix least-square analysis using SHELX-97-2 software. Nonhydrogen atoms were refined with anisotropic displacement parameter. Crystal data: $\mathrm{C}_{26}$ $\mathrm{H}_{20} \mathrm{NO}_{2} \mathrm{P}, M=409.40$, colorless needle, $0.32 \times 0.18 \times 0.12 \mathrm{~mm}^{3}$, monoclinic, space group $P 2{ }_{1} / c, a=16.096(3), \mathrm{b}=8.1863(17), \mathrm{c}=17.391(4) \AA, V=2066.7(7) \AA^{3}, Z=4$.

\section{References}

1. Clayden, J.; Pickworth, M.; Jones, L. Chem. Commun. 2009, 547-549.

2. Hou, G.; Gosselin, F.; Li, W.; McWilliams, J.; Sun, Y.; Weisel, M.; O’Shea, C.; Chen, C.; Davies, W.; Zhang, X. J. Am. Chem. Soc. 2009, 131, 9882-9883. 